\title{
Free Migration between the EU and Switzerland: Impacts on the Swiss Economy and Implications for Monetary Policy
}

\author{
Peter STAlder ${ }^{\mathrm{a}}$
}

JEL-Classification: E24, J61

Keywords: unemployment, wages, business cycle, immigration

\section{Introduction}

With a share of foreigners in total population that rose from 5\% in 1950 to more than $20 \%$ in recent years, immigration has played an important role in Switzerland's post-war economic development. While earlier waves of immigration to a large part consisted of less-qualified workers, the labor shortages more recently observed have shifted to the qualified segments of the labor market and attracted foreigners with higher skills. An agreement with the European Union that became effective in June 2002 further promoted this type of immigration because it eliminated the insecurity associated with the need to renew work permits every year. The agreement entitles citizens from EU member states to take long-term residence in Switzerland on the condition that they possess a valid work contract, with the reciprocal right for Swiss citizens to work and live in the EU. Certain quotas on the number of newly issued long-term permits remained in place in the first years of the treaty but were abolished by mid-2007. Prior to that date, firms tended to circumvent the restrictions by hiring workers from the EU for a start on basis of temporary (up to one year) permits. Another important opening step was realized in June 2004 in that Swiss firms did no longer have to give priority to job applicants already residing in Switzerland.

As a country with a relatively high standard of living, Switzerland has long been a magnet for migrants. Legal restrictions and quota on immigration have often been binding. The opening of the Swiss labor market towards the EU must

Peter Stalder, Swiss National Bank, Börsenstrasse 15, P. O. Box, CH-8022 Zurich, Switzerland. Phone: +41 4463139 64, E-mail: peter.stalder@snb.ch. The views expressed in this paper are those of the author and should not be attributed to the Swiss National Bank. 
therefore be expected to impact significantly on the cyclical and long-run behavior of the Swiss economy. ${ }^{1}$ Keeping track of such changes is important, not least with regard to the conduct of monetary policy. For example, facilitated immigration is likely to reduce the incidence of labor shortages and thus exert a dampening effect on the development of wages and inflation in economic upturns. On the other hand, the influx of migrants also affects the demand side of the economy by raising consumption and housing investment. Macroeconomic key figures like equilibrium unemployment and potential output growth may be affected by the enhanced availability of personnel as well.

One possibility to identify the effects of the migration agreement with the EU is to ask whether existing econometric models estimated on historical data still describe the current working of the Swiss economy in an appropriate way. The question is not easy to address at this time because the experiences with the new immigration regime are relatively short and largely pertain to a period characterized by a sustained upswing (2004-2008). Nevertheless, checking an existing econometric model for parameter shifts in this period may show, for example, whether labor shortages were less prevalent and inflationary pressures thus weaker compared with historical regularities. If supporting evidence for this view is found, one may incorporate the identified changes into the model in order to see to what extent they alter the behavior in different cyclical situations. This way, it should be possible to get at least a rough idea about the economic effects of the new immigration regime.

The conclusions that can be drawn from the study will remain limited for at least two reasons. First, it is questionable whether changed reactions identified in an economic upturn can be carried over symmetrically to recession periods. For example, the finding of increased upward flexibility of labor supply in the upswing 2004-2008 does not necessarily imply increased downward flexibility in a slump. A second difficulty arises from the fact that the migration flows observed in recent years reflect both transitory and permanent effects of the new legal framework. In analogy to a hydraulic system, the opening of a formerly closed valve will first elicit flows that tend to equalize pressure between the different parts of the system. Once this transition phase is completed, the dynamic behavior of the new open-valve system may differ from the old system. Separating these two effects on basis of a relatively short observation period is not easy and will involve a considerable amount of judgment.

1 An earlier study showed that the initially pronounced cyclical buffer role of foreign workers has decreased over the period 1980-2000 as a growing number of foreigners acquired permanent residence status. See STALder (2002). 
The modeling approach is described in Section 2. Section 3 presents model simulations under various assumptions about the impact of the migration agreement. Section 4 concludes and compares the paper with the existing literature.

\section{The Modeling Approach}

\subsection{Basis Structure of the Model}

The implications of liberalized immigration are studied in the framework of an existing macroeconomic model for Switzerland (STALDER, 2001). The model has 33 stochastic equations that may be assigned to demand block, a supply block and a monetary block (Figure 1).

Figure 1: Basic Structure of the Model

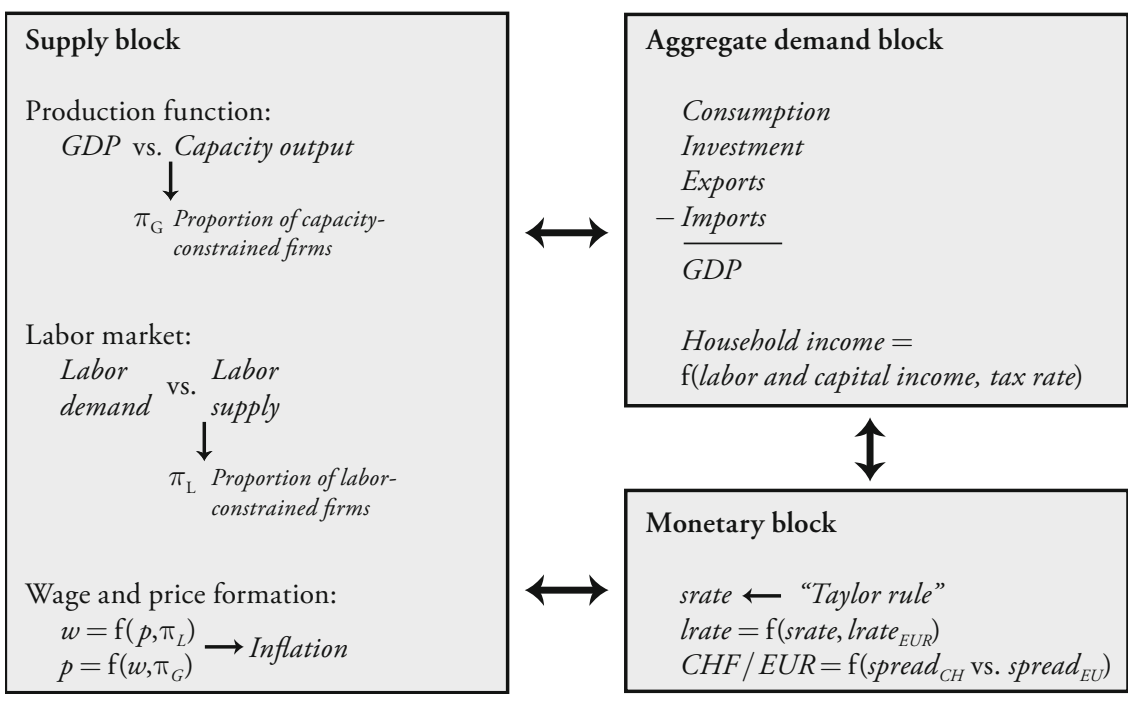

The model has Keynesian properties in the short run but converges to a classical growth path in the long run. Real GDP, determined from the demand side of the economy as the sum of the components of aggregate demand, is confronted in the supply block of the model with capacity output. The underlying production function at the same time establishes a link to the labor market, where employment depends in a 'Beveridge curve'-type approach on labor demand, labor supply 
and a measure for structural mismatch. Inflation is driven by tension in the goods market (price equation) and the labor market (wage equation), measured by the proportions of firms constrained by technical capacities $\left(\pi_{G}\right)$ and labor supply $\left(\pi_{L}\right)$, respectively. Due to sluggish price and wage adjustments, aggregate demand and monetary variables play an important role for the short-term fluctuations in the economy. As characteristic feature of the model, demand shocks are split differently between real GDP and inflation, depending on the initial state of the economy. For example, in a situation with idle resources (low $\pi_{G}$ and low $\pi_{L}$ ), a positive demand shock will strongly stimulate output and employment with little impact on inflation. While such Keynesian processes are relevant in the short run, the long run growth potential of the economy is determined by the supply side of the model. Excessive growth of nominal demand in relation to the real growth potential is absorbed by inflation.

Under normal circumstances, however, such inflationary developments are prevented by monetary policy. The monetary reaction function is in the spirit of a Taylor rule, letting the short-term interest rate (srate) respond to factors that have a lead on inflation ( $\pi_{G}$ and $\pi_{L}$, exchange rate). Alternatively, the model can be solved for a path of srate that steers CPI inflation to a desired target at a prespecified forecasting horizon. Changes in srate affect the economy via the longterm interest rate, lrate, and the CHF/EUR exchange rate.

The labor market part of the model lends itself quite naturally to the analysis of immigration issues. The relationship between labor demand, labor supply and actual employment is based on the notion that the aggregate labor market consists of a continuum of 'micro markets' characterized by different demand/ supply ratios. The variation in this ratio in the cross-section of micro markets can be viewed as a measure of structural mismatch. In each period, a subset of micro markets is in excess demand while a complementary subset of micro markets is in excess supply. The shares of the two regimes vary over the business cycle. If aggregate demand rises in relation to aggregate supply, the subset of micro markets in excess demand increases while the subset of micro markets in excess supply decreases. In the first subset, employment is supply-determined and firms are unable to fill their vacancies, which hinders production activities. This is a spillover from rationed labor demand to reduced goods supply. In the second subset of micro markets, employment is demand-determined. Workers are confronted with involuntary unemployment and therefore likely to curtail their consumer demand. This is a spillover from rationed labor supply to reduced goods demand. It may in turn constrain firms in the product market, resulting in a spillover from rationed goods supply to reduced labor demand. In a typical Keynesian situation, these two spillovers tend to reinforce each other. 
In this framework, facilitated immigration can be modeled in two different ways, namely as a selective inflow of foreign workers into micro markets that are in excess demand or as a general increase in the supply of labor. The empirical evidence supports the second view, as will be explained below. Next, the parts of the model that are most relevant in the context of this paper are described in more detail.

\subsection{Micro Labor Markets and Aggregation}

The micro labor markets mentioned above do not show up explicitly in the model but are used as a theoretical device in the derivation of the aggregate relationships. They are assumed to be narrowly defined so that a coexistence of excess supply (unemployment) and excess demand (unfilled vacancies) can be excluded at a given point of time. According to the short-side rule implied by the principle of voluntary trade under imperfect market clearing, employment on micro labor market $i$ is thus given by the minimum of demand and supply:

$$
L_{i}=\min \left(L D_{i}, L S_{i}\right)
$$

Aggregate employment $L$ then depends on the way how $L D_{i}$ and $L S_{i}$ are distributed across micro markets. Assuming a bivariate lognormal distribution, it can be shown (STALDER, 1991a; LAMbert, 1988) that the 'angular' minimum condition (1) resolves into smooth aggregate relationships that are well approximated by the following two equations:

$$
\begin{gathered}
L\left(1-\pi_{L}\right)^{-v}=L D \\
L \pi_{L}^{-v}=L S
\end{gathered}
$$

$L D$ and $L S$ are aggregate labor demand and labor supply, $L$ is aggregate employment and $\pi_{L}$ is the proportion of micro markets in excess demand, measured empirically by the percentage of firms reporting labor shortages in business surveys. Parameter $v$ is a measure of demand/supply mismatch. It is related to the variance of $\log \left(L S_{i} / L S_{i}\right)$ in the cross-section of micro markets, which may be written in terms of the parameters of the bivariate distribution of $\log \left(L D_{i}\right)$ and $\log \left(L S_{i}\right)$ as $\sigma^{2}=\sigma_{D}^{2}+\sigma_{S}^{2}-2 \rho \sigma_{D} \sigma_{S}$. Equations (2.1) and (2.2) establish a nonlinear one-to-one mapping from the two latent variables $L D$ and $L S$ - for which stochastic econometric equations will be specified - to the two observable variables $L$ and $\pi_{L}$. In order to see how this mapping works, divide (2.1) by (2.2): 


$$
\left(\frac{\pi_{L}}{1-\pi_{L}}\right)^{v}=\frac{L D}{L S}
$$

If the labor market is in an aggregate equilibrium with $L D=L S$, (2.3) implies $\pi_{L}=0.5$, i.e. micro markets are split fifty-fifty into subsets of excess demand and excess supply regimes. If $L D$ increases in relation to $L S, \pi_{L}$ according to (2.3) converges to an upper limit of 1 and aggregate employment $L$ according to (2.2) tends from below to $L S$. Conversely, if $L D$ decreases in relation to $L S, \pi_{L}$ converges to a lower limit of 0 and $L$ according to (2.1) becomes fully constrained from above by $L D$.

To illustrate things graphically, Figure 2 makes the simplifying assumption that the micro labor markets are identical with respect to $L S$ and differ only with respect to $L D_{i}$. In the situation shown in the figure, a share $\pi_{L}$ of about $30 \%$ of micro markets is in excess demand. On those micro markets, employment is constrained by labor supply. The distribution of employment is thus censored at $L S$, with the whole mass of the $L D_{i}$-distribution to the right of $L S$ concentrated into $L S$, as visualized by the dotted lines. The mean of this distribution defines average (or aggregate) employment $L$, which - due to the censoring - is lower than $L D$, the mean of the $L D_{i}$-distribution. The difference between $L D$ and $L$ defines vacancies $V$, the difference between $L S$ and $L$ defines unemployment $U$. It is easy to see that shifts in the $L D_{i}$-distribution to the left (decreasing aggregate labor demand in a recession) and the right (increasing aggregate labor demand in a boom) produce a behavior of $L$ and $\pi_{L}$, that corresponds to what equations (2.1) to (2.3) imply and trace out a Beveridge curve in $(U, V)$-space. If the variance of $L D_{i}$ as a measure of demand/supply mismatch is small (low value of parameter $v$ ), shifts in the distribution produce a quick transition from almost fully demand-constrained situations ( $\pi_{L}$ close to 0 ) to almost fully supply-constrained situations $\left(\pi_{L}\right.$ close to 1$)$. In this case, the Beveridge curve would move inwards towards the origin and become more rectangular.

On basis of (2.2), the unemployment rate implied by the model (which may differ from official figures) can be expressed as

$$
U R=1-\frac{L}{L S}=1-\pi_{L}^{v}
$$


Figure 2: Distribution of Excess Demand across Micro Labor Markets and Aggregate Employment

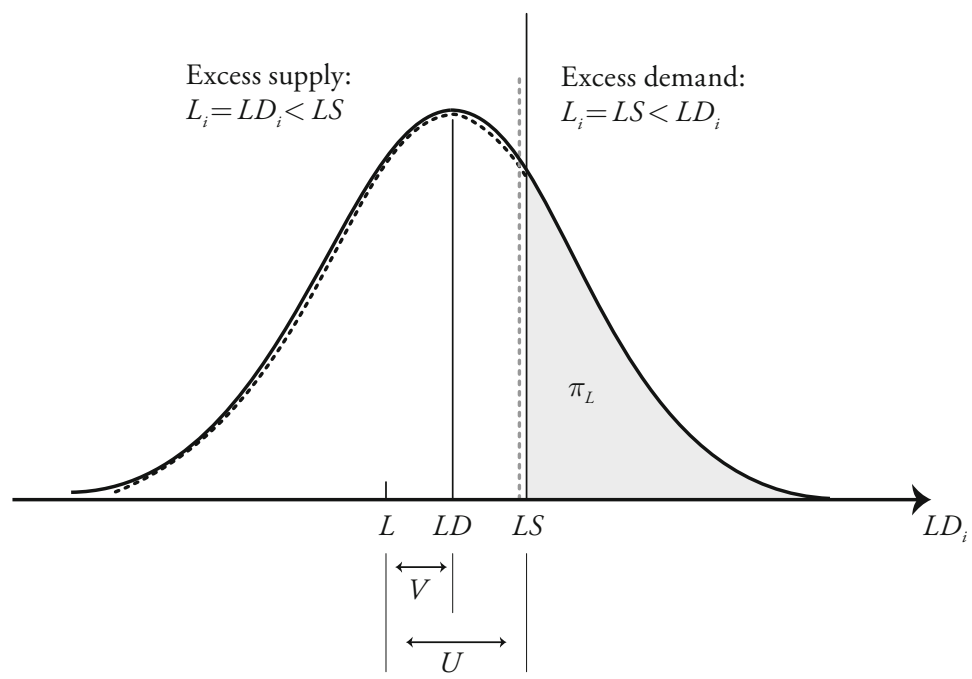

The vacancy rate implied by $(2.1)$ is

$$
V R=1-\frac{L}{L D}=1-\left(1-\pi_{L}\right)^{v}
$$

In a situation of an aggregate equilibrium $(L D=L S)$, we have $\pi_{L}=0.5$ and $L<L D=L S$. The associated unemployment rate is an increasing function of the mismatch parameter $v$ :

$$
S U R E=1-0.5^{v} \text { (structural unemployment rate at equilibrium). }
$$

Within this modeling approach, the impact of the migration agreement can idealistically - be seen as follows. Facilitated immigration allows formerly laborconstrained firms to fill their vacancies and to raise production. In a limiting situation, i.e. if all vacancies were filled, the distribution of employment across micro markets in Figure 2 (dotted line) would just coincide with the distribution 
of labor demand (bold line) and aggregate employment $L$ would move up to the level of aggregate labor demand $L D$. By abating labor bottlenecks, the agreement is also likely to increase investments in new places of work. These initial effects stimulate the overall economy and raise labor demand on micro markets in excess supply. In such a scenario, the agreement alleviates the mismatch on the labor market. It eliminates labor bottlenecks in some sectors of the economy and thereby creates positive spillover effects on other sectors, so that unemployment begins to decrease as well. This is illustrated in Figure 3 by the dotted arrow, starting from a "status quo ante" equilibrium point (NAIRU) and ending in a new equilibrium point on a Beveridge curve that has shifted inwards.

Figure 3: Migration Agreement Shifts Beveridge Curve Inwards (Idealistic View)

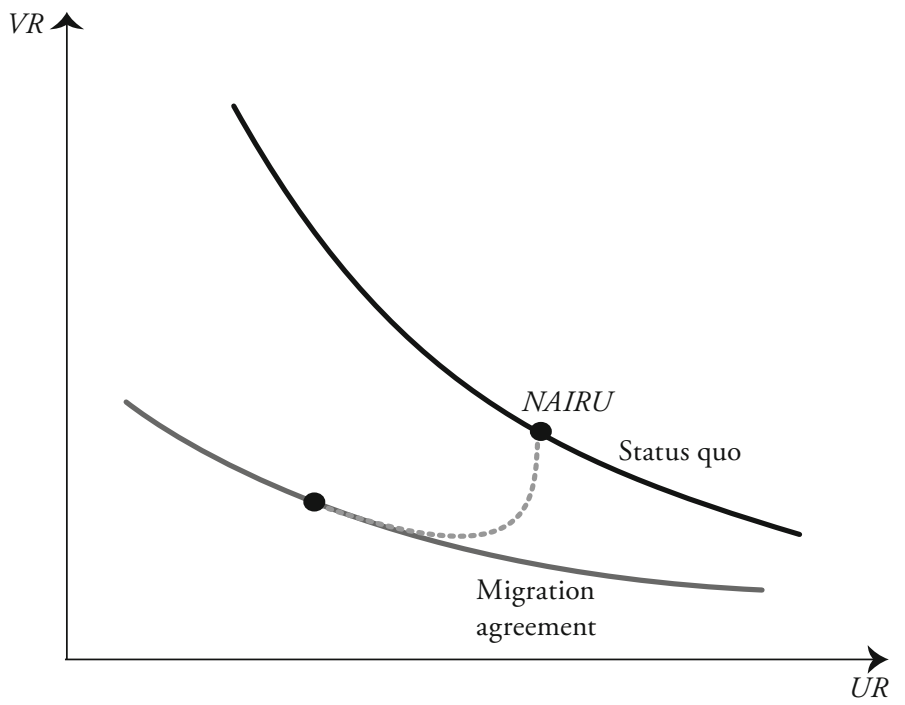

How does this optimistic scenario of a reduced labor market mismatch bear up against the facts? The critical assumption behind Figure 3 is that the new immigrants are selectively attracted to labor markets with vacancies that could not be filled otherwise. If the migration agreement in contrast leads to a general increase in the supply of labor, it may entail higher unemployment. An earlier study (STALDER, 2008) found supporting evidence for this latter view: In the upswing 
2004-2008, immigration from the EU has on the one hand mitigated the incidence of labor shortages and thus contributed to higher GDP growth from the supply side. On the other hand, the inflow of new immigrants was detrimental to the job opportunities of natives and former immigrants and thus attenuated the decline in unemployment.

Figure 4 further underpins this more realistic view of effects of the migration agreement. In contrast to what Figure 3 supposes, the empirical co-movement of unemployment and vacancies over the last two business cycles does not provide evidence of an inward shift of the Beveridge curve (panel a). What is striking, however, is the fact that recent movements in the unemployment and vacancy rate were relatively weak in relation employment developments (panel b). In the previous upswing (1997q1-2001q1), an increase in employment of 4.8\% was almost fully reflected in a falling unemployment rate. In the recent upswing (2003q2-2008q2), which took place under the migration agreement, the fall in the unemployment rate and the increase in the vacancy rate were much weaker, even though the upswing was more pronounced with employment increasing by $8.4 \%$. The explanation is that the newly created jobs were mainly filled by additional foreigners instead of hiring from the unemployment pool. In fact, as can be seen from panel c, net-immigration was exceptionally strong in recent years. Historically, net-immigration was inversely related to the Swiss unemployment rate (with some lag). In the last three years, net-immigration was much higher than what this historical relationship would have implied, which limited the fall in unemployment.

To summarize, the migration agreement with the EU does not seem to have caused an inward shift of the Beveridge curve (which could be modeled by lowering the mismatch parameter $v$ ) but rather dampened the movements along an unchanged Beveridge curve. To model this changed behavior, one has to make the equation for $L S$ - to be substituted into (2.2) - more responsive to labor market tightness (as measured by $\pi_{L}$ ). If aggregate labor demand $L D$ rises whereas aggregate labor supply $L S$ remains relatively constant, firms get increasingly labor supply-constrained. Under such historical "status quo ante" conditions, aggregate employment $L$ follows the increase in $L D$ only partly and the regime proportion $\pi_{L}$ rises strongly, implying a marked increase (decrease) in the vacancy rate $V R$ (unemployment rate $U R$ ). Under the migration agreement, however, an increase in $L D$ is likely to entail a significant increase in $L S$ so that firms get less labor-supply constrained ( $\pi_{L}$ rises by less). Aggregate employment $L$ thus follows the increase in $L D$ more closely and the reactions in the vacancy and unemployment rates are mitigated. Section 2.5 discusses in detail how the stronger cyclical response of labor supply is accounted for in the model. 
Figure 4: Recent Labor Market Developments

a) Empirical Beveridge curve, 1997q1-2009q4

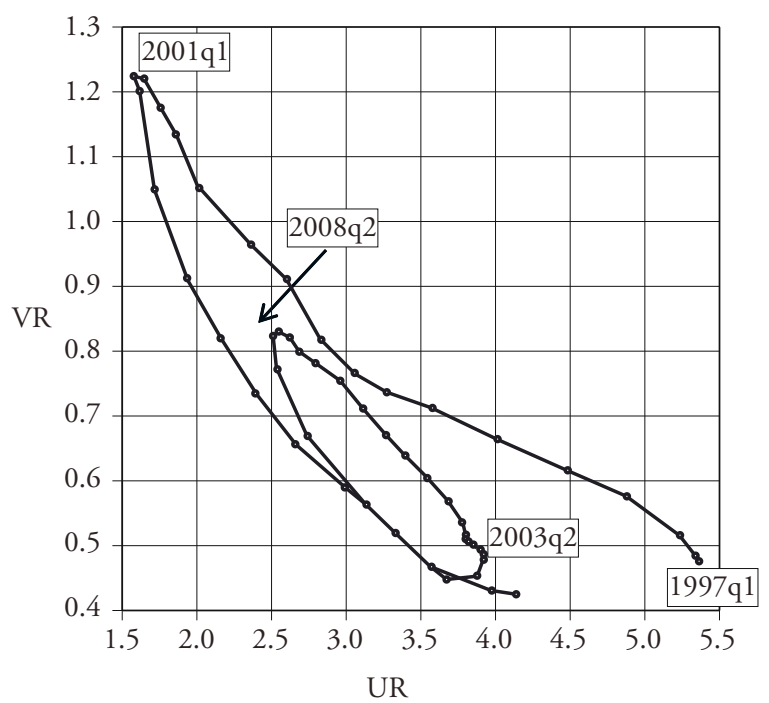

b) Employment (in 1000), 1995q1-2009q4

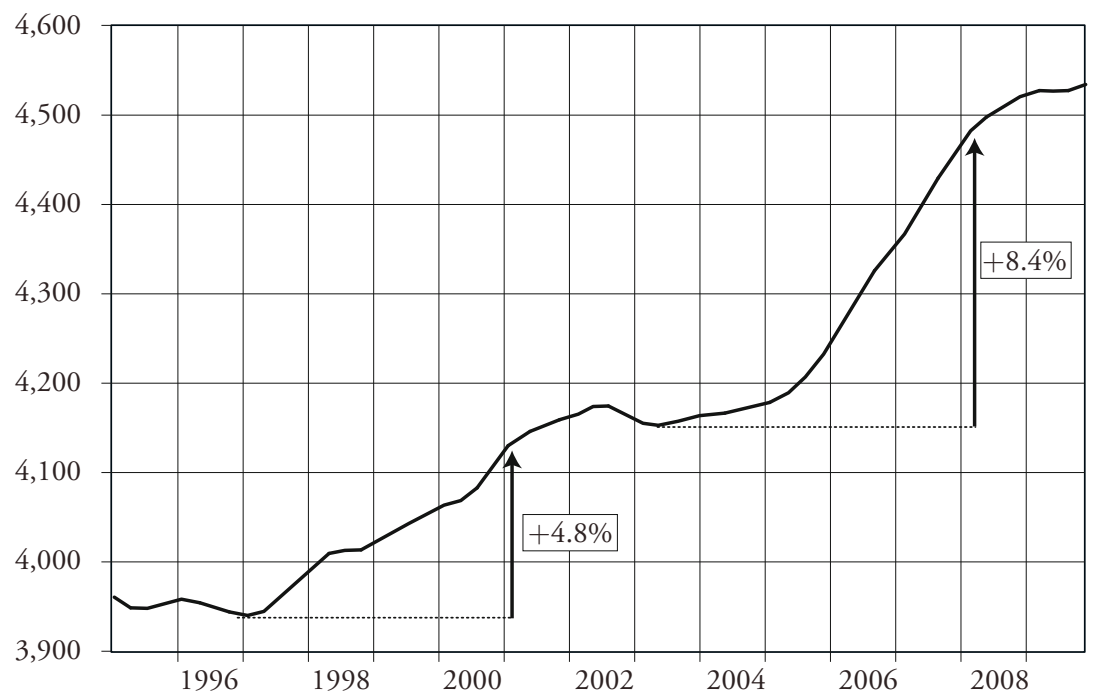


Figure 4 continued

c) Net-immigration and unemployment rate, 1981-2009

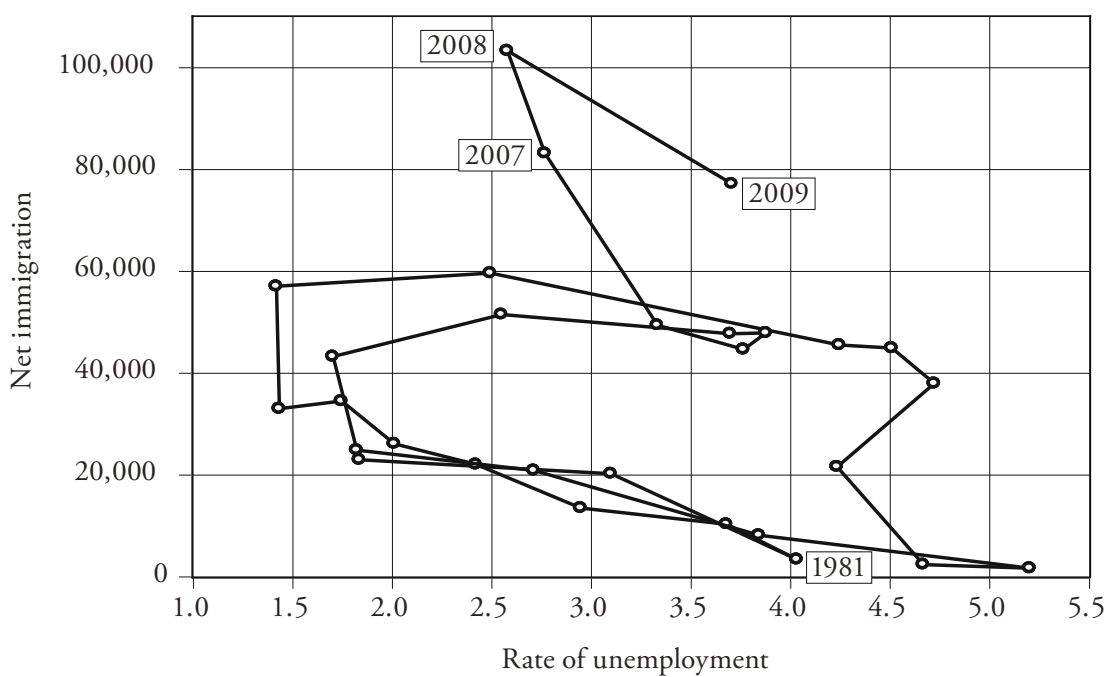

The remaining equations of the model can be sketched as follows. The development of nominal wages is made dependent on consumer prices $(p c)$, the GDP deflator $(p g d p)$, labor productivity $(Y / L)$ and the aggregate demand/supply ratio in the labor market, defined according to (2.3) in terms of $\pi_{L}$ :

$$
w=f\left(p c, p g d p, \frac{Y}{L}, \frac{\pi_{L}}{1-\pi_{L}}\right)
$$

The equation is estimated in a logarithmic error-correction form. It turns out that nominal wages respond to CPI inflation and labor market tension in the short run, whereas they are co-integrated with the GDP deflator and labor productivity in the long run in the sense of a constant functional income distribution.

The goods market is modeled in an analogous way. On the assumption of monopolistic competition, firms set the price as a profit-maximizing markup over marginal costs $M C$. In the adopted vintage framework (see below), $M C$ can be defined either as total unit costs on newly added equipment or as unit labor costs 
on oldest equipment. The two concepts are equivalent in equilibrium due to the scrapping rule, which says that old vintages get replaced as soon as the associated unit labor costs exceed total unit costs on new equipment. The profit maximizing markup price, neglecting possible capacity constraints (to be introduced below), can be written as

$$
\bar{p}=\left(\frac{\eta}{\eta-1}\right) M C
$$

where $\eta$ is the price elasticity of demand as perceived by the firm.

Desired production capacity is given by demand at the profit-maximizing price, $Y D(\bar{p})$, i.e. firms are assumed to invest in new equipment such as to bring $Y C$ into line with $Y D(\bar{p})$. In the short run, however, available production capacities may place an upper bound on output, giving rise to two possible regimes of the firm:

1. If a firm faces a demand curve which, at the optimal markup price $\bar{p}$, exceeds capacity output, it will produce at full capacity $(Y=Y C<Y D(\bar{p}))$ and temporarily raise the price $p$ above $\bar{p}$ in order to choke off excess demand.

2 . If demand at $\bar{p}$ falls short of capacity output, the firm's output level is constrained by demand $(Y=Y D(\bar{p})<Y C)$ and the price is left at $\bar{p}$.

Production at the level of the individual firm $i$ is thus given by the minimum of demand at $\bar{p}$ and the available production capacity:

$$
Y_{i}=\min \left(Y D(\bar{p})_{i}, Y C_{i}\right)
$$

Assuming a lognormal joint distribution of $Y D(\bar{p})_{i}$ and $Y C_{i}$ across firms, the aggregate relationships can be written - in analogy to the labor market equations (2.1) and (2.2) - as

$$
\begin{gathered}
Y\left(1-\pi_{G}\right)^{-\kappa}=Y D(\bar{p}), \\
Y \pi_{G}{ }^{-\kappa}=Y C,
\end{gathered}
$$

where $Y$ is aggregate output (GDP), $\pi_{G}$ is the share of capacity-constrained firms (measured by survey data) and $\kappa$ reflects the demand/capacity mismatch in the cross-section of firms.

The definition of capacity output $Y C$ differs from the more commonly used concept of potential output in two respects. First, if $Y D(\bar{p})$ increases, more and 
more firms produce at full capacity and aggregate $Y$ converges from below to $Y C$. Capacity output thus acts as an upper bound for actual output, whereas potential output is usually defined as output at an average utilization rate. Second, capacity output in contrast to potential output refers to technical capacities only. The situation on the labor market and the fact that labor shortages may also hinder production will be taken into account separately, as shown in the next paragraph.

The notion that firms facing excess demand at $\bar{p}$ raise the price can be expressed as

$$
p=\bar{p}\left(\frac{Y D(\bar{p})}{Y}\right)^{\tau}
$$

Equation (8) is estimated in an error-correction form, with (5) inserted for $\bar{p}$ and using (7.1) to measure $Y D(\bar{p}) / Y$ in terms of $\pi_{G}$. The equation says that firms raise prices in relation to marginal costs if the goods market gets tight $\left(\right.$ high $\left.\pi_{G}\right)$. Equation (4) on the other hand says that wages increase in relation to prices if the labor market gets tight (high $\pi_{L}$ ). Hence, if both markets are tight, the formation of wages and prices tends to become incompatible in the sense that the income claims of workers and firms add up to more than what is actually available for distribution. The result is a "wage-price spiral" that drives up inflation until real activity is dampened enough to make income claims compatible. Stable inflation thus requires a certain underutilization of resources. This specification of wage-price dynamics is in the spirit of the NAIRU framework devised by Layard, Nickel and Jackman (1991).

\subsection{Spillovers between Labor and Goods Markets}

Next, we introduce the quantity spillovers between the goods and the labor market that have been neglected so far. On the one hand, firms that are demandconstrained in the goods market are likely to curtail labor demand in the sense of a Keynesian spillover effect. At the aggregate level, resulting effective labor demand can be written as

$$
L D=L C \pi_{G}^{\kappa},
$$

where $L C$ is capacity labor demand (labor input corresponding to fully utilized technical capacities). If $Y D(\bar{p})$ increases in relation to $Y C, \pi_{G}$ according to (7.1)(7.2) tends to an upper limit of 1 and $Y$ converges from below to $Y C$. In such a limiting situation, effective labor demand $L D$ in (9) would coincide with capacity 
labor demand $L C$ (all available workplaces are fully operated). In general, however, $L D$ will fall short of $L C$ to the extent that $Y$ falls short of $Y C$ and $\pi_{G}^{k}$ thus falls short of 1 .

On the other hand, some firms may be unable to fully realize their labor demand. Actual output may therefore fall short of capacity output not only due to insufficient goods demand but also due to insufficient labor supply. At the micro level, this implies that min-condition (6) must be extended into

$$
Y_{i}=\min \left(Y D(\bar{p})_{i}, Y C_{i}, Y S_{i}\right),
$$

where $Y S_{i}$ is the constraint placed on output by the availability of labor. At the aggregate level, the extent to which employment falls short of labor demand is measured in (2.1) by the term $\left(1-\pi_{L}\right)^{v}$. Assuming that the spillover on output is proportional to the rationing of labor demand, equations (7.1) and (7.2) can be restated as

$$
\begin{gathered}
Y\left(1-\pi_{L}\right)^{-v}\left(1-\pi_{G}\right)^{-\kappa}=Y D(\bar{p}), \\
Y\left(1-\pi_{L}\right)^{-v} \pi_{G}{ }^{-\kappa}=Y C .
\end{gathered}
$$

Division of (11.1) by (11.2) produces the same result as division of (7.1) by (7.2), namely

$$
\left(\frac{\pi_{G}}{1-\pi_{G}}\right)^{\kappa}=\frac{Y D(\bar{p})}{Y C} .
$$

This implicates that the survey question on firms' capacity assessment (used to measure $\pi_{G}$ ) refers to a comparison of product demand with available technical capacities and is not affected by a potential labor supply constraint. For example, a firm with $Y C_{i}<Y D(\bar{p})_{i}$ is assumed to report capacities as being too small even in case that it produces below $Y C_{i}$ due to a labor shortage $\left(Y S_{i}<Y C_{i}\right)$. This makes the model recursive with respect to the determination of $\pi_{G}$ and $\pi_{L}$. First, a comparison of goods demand with capacity in (11.3) determines $\pi_{G}$. Then, given $\pi_{G}$, the resulting effective labor demand is confronted in (2.3) with labor supply, which determines $\pi_{L}{ }^{2}$. This type of interaction between markets under

2 Of course, equation (11.3) is implied by (11.1) and (11.2) and therefore redundant in the model. The same applies to equation (2.3), which is implied by (2.1) and (2.2). 
imperfect market-clearing is similar to LAMBERT (1988) or Drèze and BeAN (1990).

Equations (11.1)-(11.2) for the goods market and equations (2.1)-(2.2) for the labor market can be regarded as transformation equations, mapping the latent demand and supply variables on the right-hand side one-to-one on observables (actual market transactions and survey answering proportions) on the left-hand side. These nonlinear mappings are shaped by the two mismatch parameters, $\kappa$ and $v$, respectively. Small values of $\kappa$ and $v$ imply a quick transition from almost entirely demand-determined to almost entirely supply-determined situations as the aggregate demand moves from below through aggregate supply. Parameters $\kappa$ and $v$ are estimated by maximum likelihood along with various behavioral and technology parameters appearing in the stochastic equations substituted for the latent variables on the right-hand side of (11.1)-(11.2) and (2.1)-(2.2). For example, the equation for capacity labor demand $L C$ (to be specified below) is substituted into (9) and then linked via (2.1) to observed $L$ and $\pi_{L}$.

\subsection{Firms' Decisions on Production Capacity and Investment}

The equations for firms' decisions on production capacity, labor demand and investment are based on the assumption that "machines" can be designed to combine with an optimal amount of labor input but that factor proportions remain fixed once investment has taken place physically. The problem of the firm in such a putty-clay setting is to choose on each investment vintage the cost-minimizing factor mix, to pursue an optimal policy of replacing old investment vintages by new equipment and to adjust production capacity and labor demand to changes in goods demand and factor costs.

The evolution of capacity output $Y C_{t}$ and capacity labor demand $L C_{t}$ (employment corresponding to full utilization of the available equipment) over time $t$ is described by the following two equations:

$$
\begin{aligned}
& Y C_{t}=S_{t} Y C_{t-1}+B_{t} I_{t}, \\
& L C_{t}=S_{t} L C_{t-1}+C_{t} I_{t} .
\end{aligned}
$$

$S_{t}$ is the share of surviving equipment from the previous period, $I_{t}$ is gross investment in new equipment in period $t, B_{t}$ is capital productivity and $C_{t}$ is labor intensity of new equipment. Hence $B_{t} I_{t}$ is capacity added by vintage $t$ and $C_{t} I_{t}$ is the corresponding labor requirement. Assuming for investment vintage $t$ a 
Cobb-Douglas production function with labor share $\alpha$ and labor-augmenting technical progress $\theta$, the optimal technical coefficients are obtained as

$$
\begin{gathered}
B_{t}=B_{0} q_{t}^{-\alpha} e^{\theta \alpha t}, \\
C_{t}=C_{0} q_{t}^{-1},
\end{gathered}
$$

where $q_{t}=w_{t} / v_{t}$ is the ratio of wages to capital costs.

The expected long-term growth rate of the factor cost ratio theoretically also plays a role in the firms' optimization problem. ${ }^{3}$ On existing equipment, the factor input proportions are fixed and capital costs are 'sunk'. Existing vintages get therefore replaced as soon as the associated unit labor costs exceed total unit costs on new equipment (scrapping rule). Hence, if wages are expected to increase strongly in relation to capital costs, the prospective lifetime of new equipment shortens, the more so if this equipment is labor-intensive. Optimizing firms will therefore shift to a more capital-intensive expansion path if $q_{t}$ is expected to increase strongly. In the model, such reactions are neglected on the assumption that the expected growth rate of the factor cost ratio $q_{t}$ is constant. This can be justified empirically by the fact that the logarithm of $q_{t}$ follows a random walk with drift, implying that the innovations of the process affect the current growth rate of the factor cost ratio but leave its expected growth rate unchanged.

With respect to the scrapping decision, it is however the observed current growth rate of the factor cost ratio that matters. If wages increase strongly in relation to capital costs, a larger share of existing equipment will lose competitiveness and get scrapped. To capture the impact of the factor cost ratio $q_{t}$ on scrapping, $S_{t}$ in (12.1) and (12.2) is specified as

$$
S_{t}=(1-\delta)\left[\frac{q_{t}}{q_{t-1} \exp (\beta)}\right]^{-\xi} \text {, }
$$

where $\beta$ is the long-term average growth rate of $q_{t}, \delta$ is the long-term normal scrapping rate and $\xi$ is an empirical parameter that measures the negative impact of an increase in $q_{t}$ on the share of surviving equipment, $S_{t}$.

3 For a more thorough discussion, see STALder (1994). 
Investment behavior can be specified on basis of (12.1) by replacing $Y C_{t}$ by some concept of desired capacity, $Y C_{t}^{*}$, and solving for $I_{t}$ :

$$
I_{t}=\frac{Y C_{t}^{*}-Y C_{t-1} S_{t}}{B_{t}}
$$

To allow for adjustment cost and other factors that may cause inertia in the investment process, (15) is augmented in the empirical application by a partial adjustment scheme.

In order to make specification (15) workable, we have to define desired capacity $Y C_{t}^{*}$. Since $\bar{p}$ is the profit-maximizing markup price, one might simply equate $Y C_{t}^{*}$ to demand at this price, i.e. $Y C_{t}^{*}=Y D(\bar{p})_{t}$, implying that firms' investments tend to bring $Y C_{t}$ into line with $Y D(\bar{p})_{t}$. However, as firms may be constrained by labor supply, the question arises whether such constraints might impinge on desired capacity and thus on investment. Business surveys in fact suggest that labor shortages played an important role as an impediment to investment. ${ }^{4}$ Desired production capacity $Y C_{t}^{*}$ should therefore be defined in a way that allows for potential labor supply constraints.

To do so, we start by defining $Y D S_{i}$ as the level of output firm $i$ would aim for if only product demand and a potential labor supply constraint were taken into account:

$$
Y D S_{i}=\min \left(Y D(\bar{p})_{i}, Y S_{i}\right)
$$

Using this definition, equation (10) can be recast as

$$
Y_{i}=\min \left(Y D S_{i}, Y C_{i}\right),
$$

saying that actual output $Y_{i}$ will fall short of $Y D S_{i}$ if capacity $Y C_{i}$ is the binding constraint. It seems natural then to assume that investment in new equipment is driven by a comparison of $Y D S_{i}$ and $Y C_{i}$.

4 Such a question is regularly asked in the survey conducted by KOF (Centre for the Research of Economic Activity, ETH Zurich). The percentage of manufacturing firms reporting labor shortages as an impediment to investment peaked at $38 \%$ in 2001 . For services and construction, the corresponding numbers were $27 \%$ and $58 \%$, respectively. 
At the aggregate level, one may accordingly replace (11.1)-(11.2) by

$$
\begin{gathered}
Y\left(1-\pi_{G}^{*}\right)^{-\kappa}=Y D S, \\
Y\left(\pi_{G}^{*}\right)^{-\kappa}=Y C,
\end{gathered}
$$

where $\pi_{G}^{*}$ is now to be interpreted as the proportion of firms constrained by capacities in the modified sense that $Y D S_{i}$ - and not $Y D(\bar{p})_{i}$ - exceeds $Y C_{i}$. From the fact that $Y D S_{i} \leq Y D(\bar{p})_{i}$ it follows that $\pi_{G}^{*}$ will generally be smaller than $\pi_{G}$. Two further points should be noticed in this context. First, the micro-level mismatch between $Y D S$ and $Y C$ may be smaller or larger than the micro-level mismatch between $Y D(\bar{p})$ and $Y C$. For simplicity, however, it is assumed that the mismatch parameter $\kappa$ in (18) is the same as in (11). Second, equations (18.2) and (11.2) both link $Y$ with $Y C$, with the difference that the factor by which $Y$ falls short of $Y C$ is expressed in (18.2) in terms of $\pi_{G}^{*}$ and in (11.2) in terms of $\pi_{G}$ and $\pi_{L}$. In order for (18.2) to be congruent with (11.2), it must therefore be the case that

$$
\left(\pi_{G}^{*}\right)^{\kappa}=\left(1-\pi_{L}\right)^{v} \pi_{G}{ }^{\kappa}
$$

Using this relationship, (18.1) can be restated as

$$
Y\left(1-\left(1-\pi_{L}\right)^{v / \kappa}\right)^{-\kappa}=Y D S .
$$

This definition of $Y D S$ is substituted for desired capacity $Y C_{t}^{*}$ in the investment equation (15). ${ }^{5}$ As can be seen by comparing (18.2') with (11.1), YDS increasingly falls short of $Y D(\bar{p})$ for larger values of $\pi_{L}$ and rises towards $Y D(\bar{p})$ in a limiting situation where $\pi_{L}$ tends to zero. This is particularly relevant in the context of this paper. The possibility for Swiss firms to hire workers in the EU in case of domestic labor shortages will lower $\pi_{L}$ and thus have a positive impact not only on actual output $Y$ but also on desired capacities and thus investment.

Equation (15) is applied to equipment investment. In the complete model, this equation plays a double role, on the supply side for the development of capacity output and on the demand side as a component of aggregate demand. A detailed discussion of the equations for the other components of aggregate demand is beyond the scope of this paper. Suffice it to say that private consumption and 
housing investment depend on population growth and disposable household income. This is the channel by which immigration influences the economy from the demand side. Private consumption is moreover negatively affected by unemployment, i.e. it decreases if households are rationed by insufficient demand in the labor market. The determination of the various price variables cannot be discussed in any detail. Equations (5) and (8) refer to the GDP deflator. This is the central price variable in the model to which several other prices are linked. Consumer prices, for example, depend on the GDP deflator, import prices and housing rents. Marginal costs $M C$ in (5) should theoretically be measured as total unit costs on newly added equipment or - equivalently - as unit labor costs on oldest equipment. Both these concepts of marginal cost prove difficult empirically, though. It was therefore assumed that $M C$ moves in proportion to average unit labor cost. Finally, firms facing excess demand at $\bar{p}$ are assumed to raise the price $p$ sufficiently above $\bar{p}$ in order to eliminate excess demand. This implicates a certain value of parameter $\tau$ in (8). Hence, if $Y D(\bar{p})$ is larger than $Y$, price adjustment ensures that we have $Y D(p)=Y$. On this assumption, there is no 'rationing' of goods demand so that the various demand components of aggregate demand are directly observable in the form of market transactions as reported in the national accounts statistics. The variable $Y D(\bar{p})$ nonetheless plays an important role in the model because it governs firms' investment decision and determines by how much prices must be raised in order to bring aggregate demand into line with available capacities. The negative price elasticity of aggregate demand is mainly established via the impact of real exchange rate on exports and imports. Moreover, the Taylor principle included in the monetary reaction function ensures that higher inflation dampens economic activity through an increase in the real interest rate.

\subsection{Immigration, Labor Supply and Population Growth}

This section presents the equations dealing with labor supply and population growth and shows how these equations are affected by the new immigration regime. As a background, a quick glance at some demographic key figures is useful.

In 2008 Switzerland counted 7.6 Mio permanent residents (POP), of which 6.0 Mio were Swiss citizens (POP_S) and 1.6 Mio foreigners with long-term residence permits $\left(P O P_{-} F\right)$. The number of permanent residents in working age (16 to 64), also referred to as potential labor force, was 5.2 Mio $(L F)$, consisting of 4.0 Mio Swiss citizens $\left(L F \_S\right)$ and 1.2 Mio foreigners with long-term residence permits $\left(L F \_F\right)$. Total employment was 4.5 Mio $(L)$, of which 4.2 Mio were permanent 
residents $\left(L_{-} P\right)$ and 0.3 Mio were temporary and cross-border workers $\left(L_{-} T\right)$. Temporary workers $(0.1 \mathrm{Mio})$ may stay in Switzerland for up to one year, and cross-border workers (0.2 Mio) reside abroad and commute to work.

For temporary and cross-border workers, the distinction in (2.2) between labor supply and employment does not make sense because their presence in Switzerland is linked to a work contract. Equations (2.1) and (2.2) are therefore modified as follows:

$$
\begin{aligned}
& L\left(1-\pi_{L}\right)^{-v}=L D, \\
& L_{-} P \pi_{L}^{-v}=L S_{-} P, \\
& L=L_{-} P+L_{-} T .
\end{aligned}
$$

Temporary and cross-border workers $\left(L_{-} T\right)$ are added up in (19.3) with employment of permanent residents $\left(L_{-} P\right)$ to obtain total employment $L$, which is related in (19.1) to aggregate labor demand $L D$. Equation (19.2), on the other hand, links $L \_P$ with labor supply of permanent residents, $L S \_P$. The unemployment rate is accordingly defined as

$$
U R=1-\frac{L_{-} P}{L S_{-} P} .
$$

For given values of $L D, L S_{-} P$ and $L_{-} T$, equations (19) determine total employment $L$, employment of permanent residents $L_{-} P$, the regime proportion $\pi_{L}$ and the unemployment rate $U R$. For example, if we set the mismatch parameter $v$ to 0.03 and assume $L D=100, L S_{-} P=100$ and $L_{-} T=0$, the solution of (19) is $L=L_{-} P=97.9, \pi_{L}=0.5$ and $U R=0.021$. Starting from this initial situation, Figure 5 shows the responses in these variables to 'exogenous' variations in $L S \_P, L D$ and $L \_T$ :

- First, we let $L S \_P$ increase from 100 to 110 while keeping $L D$ at 100 and $L_{-} T$ at 0 . The outcome is shown in Figure 5a. As labor supply increases, the proportion $\pi_{L}$ of labor-constrained firms falls from 0.5 to 0.04 , employment converges from below to labor demand and the unemployment rate increases from $2.1 \%$ to $9.2 \%$.

- Second, we let $L D$ increase from 100 to 110 while keeping $L S$ at 100 and $L_{-} T$ at 0 (Figure $5 \mathrm{~b}$ ). Rising labor demand lets the proportion $\pi_{L}$ of labor-constrained 
Figure 5: Reaction of Employment $(L)$, the Proportion of Labor-Constrained Firms $\left(\pi_{L}\right)$ and the Unemployment Rate (UR) to ...

a) ... Increasing Labor Supply $\left(L S \_P\right)$
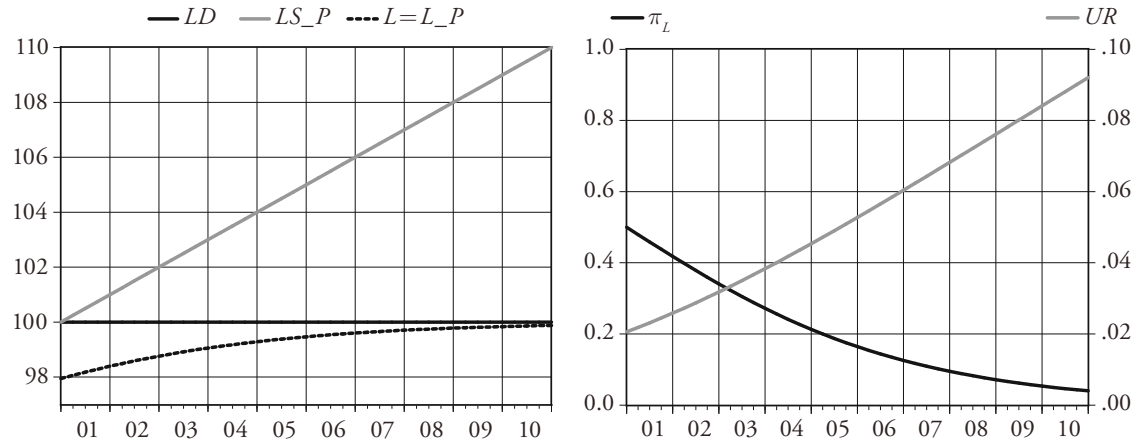

\section{b) ... Increasing Labor Demand $(L D)$}
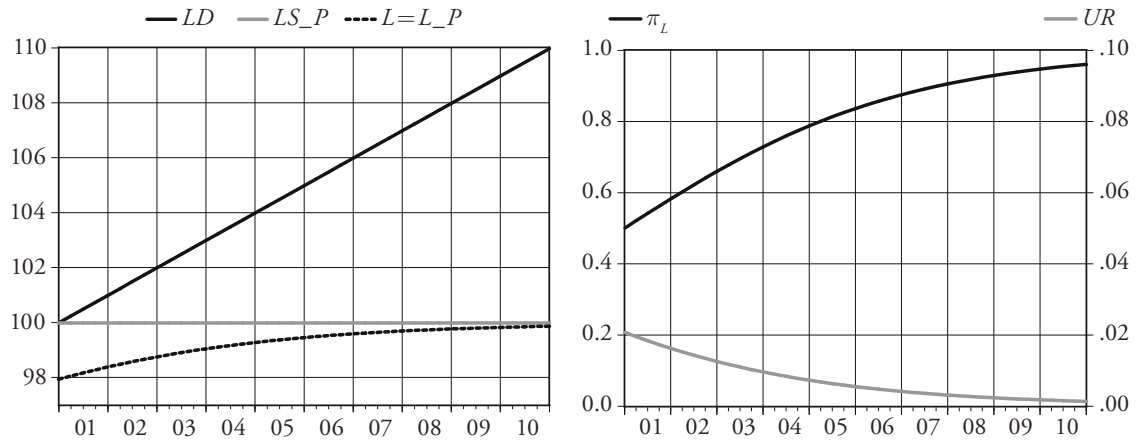

c) ... Increasing Number of Temporary Workers $\left(L_{-} T\right)$

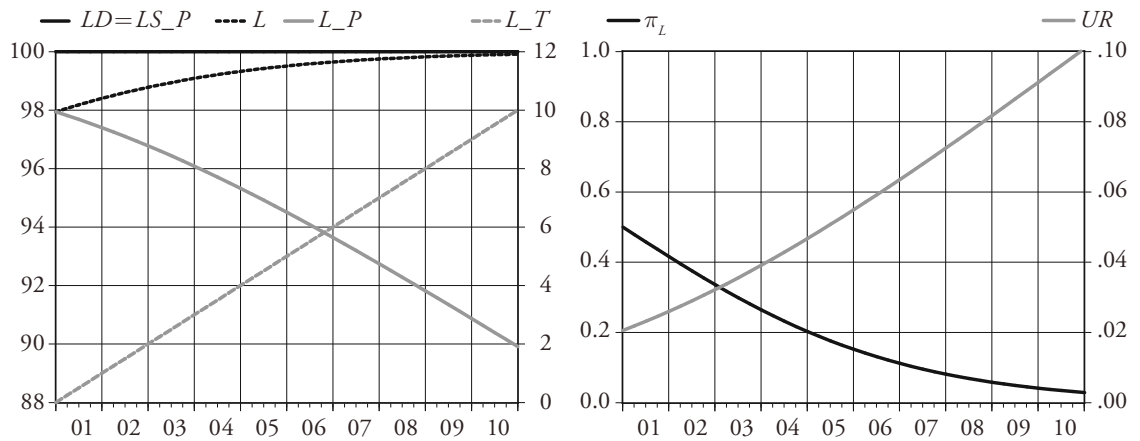


firms increase from 0.50 to 0.96 . Employment converges from below to labor supply and the unemployment rate falls from $2.1 \%$ to $0.1 \%$.

- Third, we let $L \_T$ increase from 0 to 10 while keeping $L D$ and $L S \_P$ at 100 (Figure 5c). With unchanged labor demand, the labor market does not offer much room for higher employment. Hence, the exogenous increase in the number of temporary and cross-border workers "crowds out" employment of permanent residents. $L_{-} P$ falls by 8 (from 97.9 to 89.9 ) while total employment $L$ increases only by 2 (from 97.9 to 99.9). The proportion $\pi_{L}$ of laborconstrained firms falls from 0.5 to 0.03 and the unemployment rate rises from $2.1 \%$ to $10.1 \%$.

In the complete model, the three variables treated as 'exogenous' in these though experiments ( $L S \_P, L D$ and $L_{-} T$ ) are of course endogenous, which gives rise to equilibrating counter-reactions. For example, if additional foreign workers push into the labor market, the resulting rise in unemployment will counteract further immigration.

From the equations that endogenize $L S_{-} P, L D$ and $L_{-} T$, the determination of labor demand has already been discussed: Effective labor demand $L D$ is derived from capacity labor demand $L C$ in (9), which is obtained by substituting (14) and (13.2) into (12.2). The specification of the equations for $L S_{-} P$ and $L_{-} T$ is discussed next.

Labor supply of permanent residents, $L S \_P$, is made dependent on the potential labor force $L F$ and the real consumer wage $W / C P I$. From the two components of $L F$, the foreign part $\left(L F_{-} F\right)$ is strongly pro-cyclical whereas the Swiss part $\left(L F_{-} S\right)$ is growing rather slowly and smoothly over time. $L F_{-} F$ is modeled as a function of the proportion $\pi_{L}$ of labor-constrained firms while $L F_{-} S$ is left exogenous. Disregarding details of specification, which will be discussed below, the supply side of the labor market thus looks as follows:

$$
\begin{array}{ll}
L S_{-} P=f(L F, W / C P I) & \text { Labor supply of permanent residents } \\
L F=L F_{-} S+L F_{-} F & \begin{array}{l}
\text { Potential labor force (permanent residents } \\
\text { in working age 16-64) }
\end{array} \\
L F_{-} F=f\left(\pi_{L}\right) & \begin{array}{l}
\text { Foreign potential labor force (foreign per- } \\
\text { manent residents in working age 16-64) }
\end{array}
\end{array}
$$

The number of temporary and cross-border workers is also strongly cyclical and modeled as a function of $\pi_{L}$ :

$$
L_{-} T=f\left(\pi_{L}\right)
$$


Finally, the number of permanent residents $(P O P)$, which enters the equations for private consumption and housing investment, consists of a pro-cyclical foreign part $\left(P O P_{-} F\right)$ and a slowly and steadily growing Swiss part $\left(P O P_{-} S\right) . P O P_{-} F$ is made dependent on $\pi_{L}$ whereas $P O P_{-} S$ is treated as exogenous:

$$
\begin{aligned}
P O P=P O P_{-} S+P O P_{-} F & \text { Resident population } \\
P O P_{-} F=f\left(\pi_{L}\right) & \text { Foreign resident population }
\end{aligned}
$$

The equations $L F \_F=f\left(\pi_{L}\right), L_{-} T=f\left(\pi_{L}\right)$ and $P O P_{-} F=f\left(\pi_{L}\right)$ are those through which the new immigration regime acts on the Swiss economy. Roughly speaking, the migration agreement with the EU makes $L F_{-} F, L_{-} T$ and $P O P_{-} F$ more responsive to changing labor market tension as measured by $\pi_{L}$. This is now explained in detail.

Table 1: Temporary and Cross-Border Workers $L \_T$

$$
\begin{aligned}
\Delta \log \left(L_{-} T_{t}\right) & =-b_{1}\left(1+b_{1}^{d} D S_{t}\right) \Delta \log \left(1-\pi_{L t}\right) \\
& -\gamma\left(\begin{array}{l}
\log \left(L_{-} T_{t-1}\right)-\left(\beta_{0}+\beta_{0}^{d} D T_{t}\right) \\
+\beta_{1}\left(1+\beta_{1}^{d} D S_{t}\right) \log \left(1-\pi_{L t-1}\right)
\end{array}\right)
\end{aligned}
$$

\begin{tabular}{lccc}
\hline & Value & Std Err & T-Stat \\
\hline$b_{1}$ & 0.190846 & 0.041906 & 4.554121 \\
$\gamma$ & 0.066133 & 0.016992 & 3.891942 \\
$\beta_{0}$ & 4.202376 & 0.110358 & 38.07966 \\
$\beta_{0}{ }^{d}$ & 0.372518 & 0.106429 & 3.500142 \\
$\beta_{1}$ & 1.154319 & 0.242363 & 4.762768 \\
$b_{1}{ }^{d}=\beta_{1}{ }^{d}$ & 0.679458 & 0.236660 & 2.871027 \\
\hline
\end{tabular}

$\mathrm{RSQ}=0.34876 ; \mathrm{SER}=0.01968 ; \mathrm{DW}=2.33488$

Estimation period $1981 \mathrm{q} 1$ to $2008 \mathrm{q} 4$

Equation (20) for the number of temporary and cross-border workers is estimated by FIML in the framework of the model's supply block. It has an 'error-correction' form, involving a long-run level relationship between $\log \left(L_{-} T\right)$ and $-\log \left(1-\pi_{L}\right)$. For the latter term, which measures tension in the labor market, several versions 
Table 2: Foreign Potential Labor Force (Permanent Foreign Residents, Age Range 16 to 64) $L F_{-} F$

$$
\begin{aligned}
\Delta^{2} \log \left(L F_{-} F_{t}\right)= & -\left(b_{1}+b_{1}^{d} D S_{t}\right) \Delta \log \left(1-\pi_{L t-1}\right) \\
& -\gamma\left(\begin{array}{l}
\Delta \log \left(L F_{-} F_{t-1}\right)-\left(\beta_{0}+\beta_{0}^{d} D C_{t}\right) \\
+\left(\beta_{1}+\beta_{1}^{d} D S_{t}\right) \log \left(1-\left(\pi_{L t-2}\right)\right.
\end{array}\right)
\end{aligned}
$$

\begin{tabular}{lccr}
\hline & Value & Std Err & T-Stat \\
\hline$b_{1}$ & 0.006168 & 0.000647 & 9.535988 \\
$b_{1}{ }^{d}$ & 0.034929 & 0.004367 & 7.998409 \\
$\gamma$ & 0.045241 & 0.013662 & 3.311420 \\
$\beta_{0}$ & -0.005030 & 0.002279 & -2.206577 \\
$\beta_{0}{ }^{d}$ & 0.002607 & 0.001670 & 1.561760 \\
$\beta_{1}$ & 0.023968 & 0.004862 & 4.929660 \\
$\beta_{1}{ }^{d}$ & 0 (admissible & & \\
& constraint: $t=0.280)$ & & \\
\hline
\end{tabular}

$\mathrm{RSQ}=0.69648 ; \mathrm{SER}=0.00028 ; \mathrm{DW}=0.54466$

Estimation period $1981 \mathrm{q} 1$ to $2008 \mathrm{q} 4$

have been tried. The retained version, $-\log \left(1-\pi_{L}\right)$, is proportional to the excess of labor demand over actual employment, i.e. the vacancy rate, as can be seen from (19.1) or (2.1). Equation (20) thus says that higher (lower) excess demand for labor attracts a larger (smaller) number of temporary and cross-border workers. The long-run (short-run) reaction of $L_{-} T$ to excess demand for labor is measured by parameter $\beta_{1}\left(b_{1}\right)$. The possibility that new immigration regime strengthens these reactions is captured by the terms $\beta_{1}^{d} D S$ and $b_{1}^{d} D S$, where $D S$ is a dummy variable for which a jump from 0 to 1 in 2005 q1 turns out to be optimal on a likelihood criterion. The estimation shows that the new immigration regime has raised both reaction coefficients by $67.9 \%$. The constraint $b_{1}^{d}=\beta_{1}^{d}$ is accepted by the data with practically no loss in likelihood.

The empirical analysis further points to a temporary upward shift in $L_{-} T$ that was unrelated to excess demand. This shift is captured by the term $\beta_{0}^{d} D T$, where $D T$ is a dummy variable that jumps from 0 to 1 in $2002 \mathrm{q} 2$ and back to 0 in 2007q1. As mentioned in the introduction, in the first years of the agreement with the EU, firms tended to circumvent the still existing quotas for longterm permits by hiring foreign workers for a start on basis of temporary permits. 
According to the estimation results, the number of temporary and cross-border workers rose by $45 \%$ due to this behavior $\left(\exp \left(\beta_{0}^{d}\right)=1.45\right)$. The rather low value of the error-correction parameter $\gamma$ implies that the increase took place continuously over the period 2002q1 to 2006q4. From 2007q1 onwards, as D2 is switched off, the increase was reversed as workers entering Switzerland on basis of temporary permits acquired long-term residence status.

To summarize, the migration agreement with the EU has markedly enhanced the cyclical impact of labor market tightness on the number of temporary and cross-border workers from 2005q1 onwards. In addition, the agreement had a strong temporary effect on the size of this group of workers in the period 2002 to 2006 .

Equation (21) for the foreign potential labor force is also estimated by FIML within the model's supply block over the period 1981q1 to 2008q4. It has a structure similar to equation (20), with the notable difference that the error-correction term posits a long-run relationship between the level of excess demand for labor $\left(-\log \left(1-\pi_{L}\right)\right)$ and the growth rate (and not the level) of $L F_{-} F$. The equation thus implies that higher excess demand for labor entails a faster growing foreign potential labor force. Accordingly, the dependent variable of the equation is the second difference of $\log \left(L F_{-} F\right)$, i.e. the change in the quarterly growth rate of $L F_{-} F$. A disturbing estimation problem results from the fact that data for $L F \_F$ is only available on an annual basis. The quarterly series was obtained by interpolating the annual observations with a spline-function. This gives rise to autocorrelation in the dependent variable $(\rho=0.932)$ and - unfortunately - also in the error term of the equation $(D W=0.545, \rho=0.728)$. Therefore, the reported $t$-statistics tend to overstate the significance of the parameter estimates.

The impact of the new migration regime is captured by two $(0,1)$-dummy variables. For $D S$, affecting the "slope" parameters, the optimal switching point on a likelihood criterion is in $2005 \mathrm{q} 1$. The dummy coefficient $\beta_{1}^{d}$ turned out to be insignificant $(t=0.280)$ and was thus constrained to zero, implying that the new immigration regime has not strengthened the impact of excess labor demand on the long-run growth rate of $L F \_F$. The other dummy variable, $D C$, affects the constant term of the equation. The optimal switching point is $2002 \mathrm{q} 2$, and the estimate for the related coefficient is $\beta_{0}^{d}=0.0026$, implying that the growth rate of $L F_{-} F$ has increased by about $1 \%$ on an annual basis since $2002 \mathrm{q} 2$, independently of market tension. This can be interpreted as the transitory effect of the introduction of the new immigration regime. However, the statistical significance of this effect is not overwhelming, the more so as the reported $t$-value of 1.56 is likely to be overestimated. Hence, one might argue that the entire error-correction term of the equation, which determines the long-run growth rate of $L F_{-} F$, is not 
Table 3: Foreign Resident Population POP_F

$$
\begin{aligned}
\Delta^{2} \log \left(P O P_{-} F_{t}\right) & =-\left(b_{1}+b_{1}^{d} D S_{t}\right) \Delta \log \left(1-\pi_{L t-1}\right) \\
& -\gamma\left(\begin{array}{l}
\Delta \log \left(P O P_{-} F_{t-1}\right)-\left(\beta_{0}+\beta_{0}^{d} D C_{t}\right) \\
+\left(\beta_{1}+\beta_{1}^{d} D S_{t}\right) \Delta \log \left(1-\pi_{L t-2}\right)
\end{array}\right)
\end{aligned}
$$

\begin{tabular}{lccc}
\hline & Value & Std Err & T-Stat \\
\hline$b_{1}$ & 0.006023 & 0.000705 & 8.547435 \\
$b_{1}{ }^{d}$ & 0.032044 & 0.005132 & 6.243951 \\
$\gamma$ & 0.027995 & 0.010179 & 2.750386 \\
$\beta_{0}$ & -0.014118 & 0.006235 & -2.264110 \\
$\beta_{0}{ }^{d}$ & 0.007630 & 0.004453 & 1.713528 \\
$\beta_{1}$ & 0.045201 & 0.014338 & 3.152530 \\
$\beta_{1}{ }^{d}$ & 0 (admissible & & \\
& constraint: $t=0.205)$ & & \\
\hline
\end{tabular}

$\mathrm{RSQ}=0.70118 ; \mathrm{SER}=0.00029 ; \mathrm{DW}=0.54929$

Estimation period $1981 \mathrm{q} 1$ to $2008 \mathrm{q} 4$

affected by the migration agreement. In contrast, the short-run dynamics change significantly. The coefficient that measures the impact of the change in excess demand on the change in the growth rate of $L F_{-} F$ increases from $b_{1}=0.0062$ prior to 2005 to $b_{1}+b_{1}^{d}=0.0411$ from 2005 onwards. To assess the importance of this parameter shift, assume that the proportion $\pi_{L}$ of firms facing labor shortages increases from 0.3 to 0.4 (which is well within the historical variation). This raises the annualized growth rate of $L F \_F$ by 0.4 percentage points prior to 2005 but by 2.5 percentage points thereafter.

Another illuminating comparison is between the short-run and long-run impact of excess labor demand on the growth rate of $L F \_F$. Prior to 2005, the short-run impact $\left(b_{1}=0.0062\right)$ was much weaker than the long-run impact $\left(\beta_{1}=0.0240\right)$. Together with the small value of the error-correction parameter $\gamma$, this implies that the growth rate of $L F \_F$ responded only slowly to excess demand for labor. But from 2005 onwards, the short-run impact $\left(b_{1}+b_{1}{ }^{d}=0.0411\right)$ is even larger than the (unchanged) long-run impact. This implies that higher excess labor demand is immediately reflected in faster growth of $L F \_F$.

To summarize, we may conclude that the agreement with the EU on liberalized migration has left the size of the reaction in the growth rate of the permanent 
foreign labor force to excess labor demand unchanged but has substantially raised the reaction speed.

Equation (22) for the foreign residential population is specified exactly as equation (21). The estimation results are also very similar, which is not surprising since foreign residents in the age range 16 to $64\left(L F \_F\right)$ account for about $75 \%$ of all foreign residents $\left(P O P_{-} F\right)$. A detailed discussion of the estimation results can thus be left to the reader. The main conclusion to be drawn is analogous to equation (21): Liberalized immigration did not affect the overall response in the growth rate of permanent foreign residents to excess labor demand but has raised the speed of the reaction substantially.

\section{Simulation Results}

\subsection{Preliminary Remarks}

As shown in the preceding section, there are three channels through which the agreement with the EU on liberalized migration affects the Swiss economy: First, excess demand for labor raises the growth rate of foreign potential labor force $(L F-F)$ more quickly. This carries over to the overall potential labor force $(L F)$ and labor supply of permanent residents $\left(L S_{-} P\right)$. Second, excess demand for labor attracts a larger number of temporary and cross-border workers $\left(L_{-} T\right)$. In an economic upswing, these two effects mitigate the incidence of labor shortages, dampen inflation and give leeway to higher GDP growth from the supply side. Third, the new immigration regime also affects the demand side of the economy: Excess demand for labor raises the growth rate of the foreign population $\left(P O P \_F\right)$ more quickly. Higher population growth stimulates GDP growth from the demand side via increased private consumption and housing investment, thereby counteracting the inflation dampening supply-side effect of increased immigration to some extent. In what follows, the magnitude and macroeconomic interaction of these effects will be assessed by means of simulations with the complete model. Beforehand, some difficulties in the design of the simulation experiments must be mentioned.

The estimation results for equations (20) to (22) suggest that the new migration agreement began to attract an increasing number of foreigners from $2002 \mathrm{q} 2$ onwards. At this time, the Swiss economy was on a downturn and unemployment rising. The effects of the migration agreement in this phase are accordingly captured by upward shifts in the constant terms of the equations, whereas the "slope"-parameters, measuring the reaction to excess labor demand, assume 
larger values from 2005q1 onwards, when the Swiss economy took off for a long-lasting upswing. As the latter effects are estimated over a boom period, it is questionable whether they can be symmetrically carried over to recession periods. Put differently, the finding of increased upward flexibility of labor supply in an upturn does not necessarily imply increased downward flexibility in a downturn. Another difficulty in the design of the simulation experiments arises from the fact that the immigration flows observed in recent years reflect both transitory and permanent effects of the migration agreement with the EU. How can we distinguish between the transitory one-off effects that resulted from opening up the Swiss labor market to immigration and the permanently changed functioning of the Swiss economy once the transition to the new regime is completed? A tenable, although by no means incontestable solution is to assume that shifts in the constant terms of the equations reflect the transitory effects, whereas the changes in the slope parameters capture the permanent effects.

\subsection{Hypothetical Development 2002 to 2008 without Liberalized Migration}

The first simulation experiment is not affected by the difficulties just mentioned because it does not try to generalize the estimation results beyond the period over which the parameter shifts have been identified. The aim is simply to show how the Swiss economy would have developed in the period 2002 to 2008 without the migration agreement, under "status quo ante" conditions, so to speak. Technically, the parameter shifts that capture the effects of the agreement in the baseline simulation are suppressed in the counterfactual "status quo ante" alternative. For presentational reasons, both the baseline and the alternative simulation include the historical residuals of the model. This has the advantage that the baseline simulation exactly reproduces the actual course of the economy. Otherwise, one would have to compare the alternative simulation with a baseline simulation which itself deviates to some extent from actual developments.

In the following simulations, the parameter shifts in equations (20), (21) and (22) are first suppressed individually (ALT1, ALT2, ALT3) and then jointly (ALT4):

ALT1: $b_{1}^{d}=0$ and $\beta_{0}^{d}=0$ in equation (21)

Behavior of $L F \_F$ (foreign potential labor force) reset to "status quo ante" conditions.

ALT2: $b_{1}^{d}=0$ and $\beta_{0}^{d}=0$ in equation (22)

Behavior of POP_F (foreign resident population) reset to "status quo ante" conditions. 
ALT3: $b_{1}^{d}=\beta_{1}^{d}=0$ and $\beta_{0}^{d}=0$ in equation (20)

Behavior of $L_{-} T$ (temporary and cross-border workers) reset to "status quo ante" conditions.

ALT4:

Behavior of $L F_{-} F, P O P_{-} F$ and $L_{-} T$ reset to "status quo ante" conditions.

While it is analytically interesting to look at the changes in the three equations individually, it is also clear that in reality they are interrelated. In particular, if $L F_{-} F$ is assumed to behave according to "status quo ante" conditions, this necessarily applies to $P O P_{-} F$ as well because foreign residents in working age account for about $75 \%$ of all foreign residents. Simulation results are shown in Figure 6.

Simulation ALT1 suppresses the impact of the migration agreement on the development of $L F \_F$ (foreign potential labor force). This strongly reduces the increase in this variable. At the end of the simulation period (2008q4), the simulated growth rate is $1 \%$ versus $4 \%$ actually. As a result, the unemployment rate increases by less in 2003 and falls by more in the following years, reaching a trough of $2.0 \%$ in 2008 instead of $2.5 \%$ actually. Lower unemployment is accompanied by a higher proportion $\pi_{L}$ of firms facing labor shortages, which in turn lifts the growth rates of $L_{-} T$ (temporary and cross-border workers) and POP_F (foreign resident population). As already mentioned, the combination of lower growth in $L F_{-} F$ and higher growth in the $P_{P_{-}} F$ is unrealistic because $L F_{-} F$ is part of $P O P_{-} F$. It is conceivable though that firms would react to a reduced availability of foreigners with long-term residence permits by hiring more temporary and cross-border workers. The higher $\pi_{L}$ also feeds positively back on $L F_{-} F$ itself. GDP growth is only weakly affected. On the one hand, lower growth of $L F_{-} F$ constrains GDP growth from the supply side. On the other hand, stronger growth in POP_F stimulates GDP growth from the demand side. While these two effects are countervailing with respect to GDP growth, they both raise inflation. Inflation as measured by the GDP deflator (CPI) exceeds actual values by $0.6(0.4)$ percentage points by 2008 .

Simulation ALT2 suppresses the impact of the migration agreement on the growth rate of $P O P_{-} F$ (foreign resident population). This change of behavior, if taken individually, amounts to a simple negative demand effect: Lower population growth dampens private consumption and housing investment. GDP growth and inflation are thus lowered, while unemployment is raised. Higher unemployment on the one hand reinforces the decline in foreign population growth. On the other hand, it also acts negatively on the development of foreign labor (both $L F_{-} F$ and $L_{-} T$ ), which partly counteracts the increase in unemployment. 
Figure 6: Development of the Swiss Economy in the Absence of Liberalized Immigration

ALT1: $L F_{-} F$ (foreign potential labor force) reset to "status quo ante" behavior

ALT2: $P O P_{-} F$ (foreign resident population) reset to "status quo ante" behavior

ALT3: $L_{-} T$ (temporary and cross-border workers) reset to "status quo ante" behavior

ALT4: $L F_{-} F, P O P_{-} F$ and $L_{-} T$ reset to "status quo ante" behavior

a) Foreign Potential Labor Force (y-on-y change in \%)

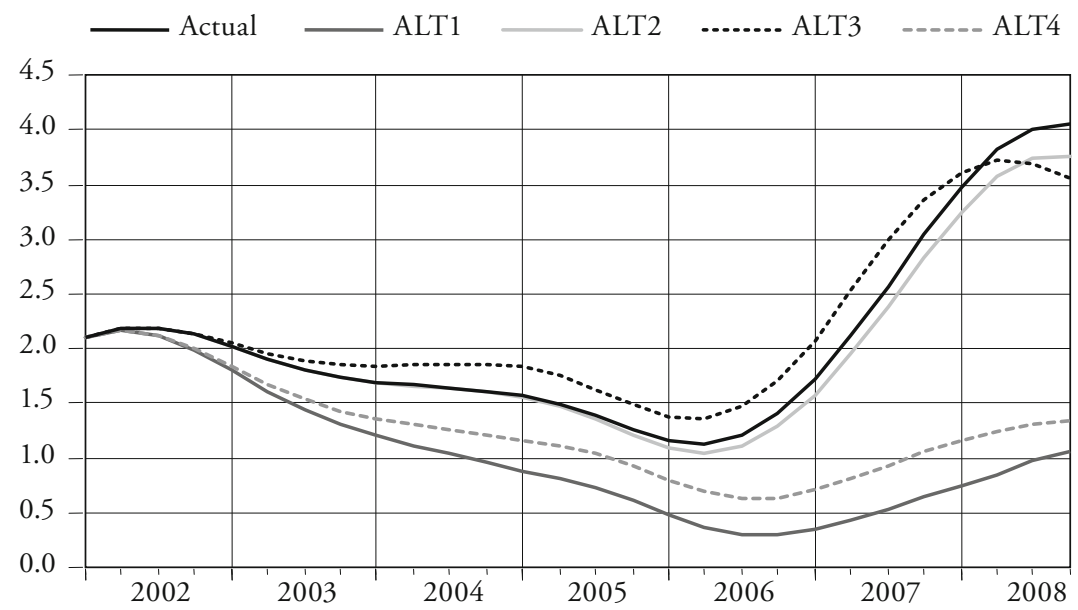

b) Foreign Resident Population (y-on-y change in \%)

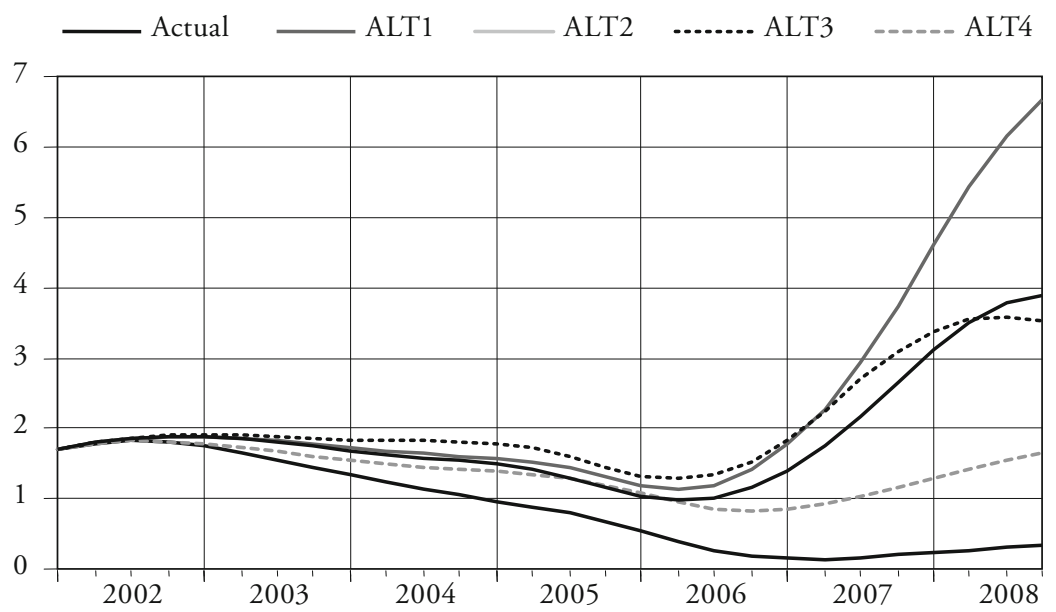




\section{Figure 6 continued}

c) Temporary and Cross-Border Workers (y-on-y change in \%)

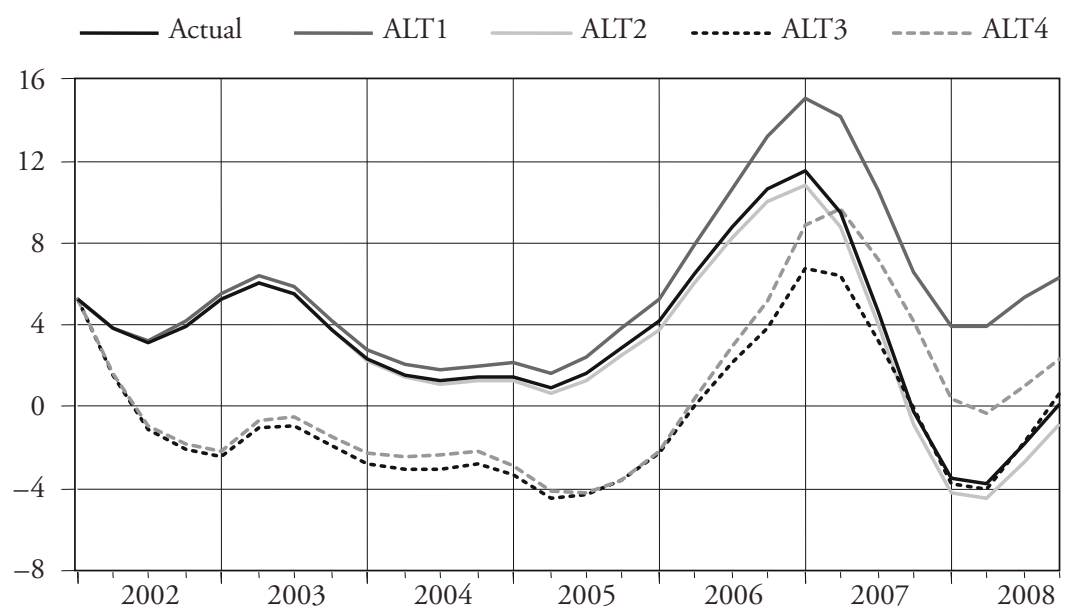

d) Unemployment Rate (in \%)

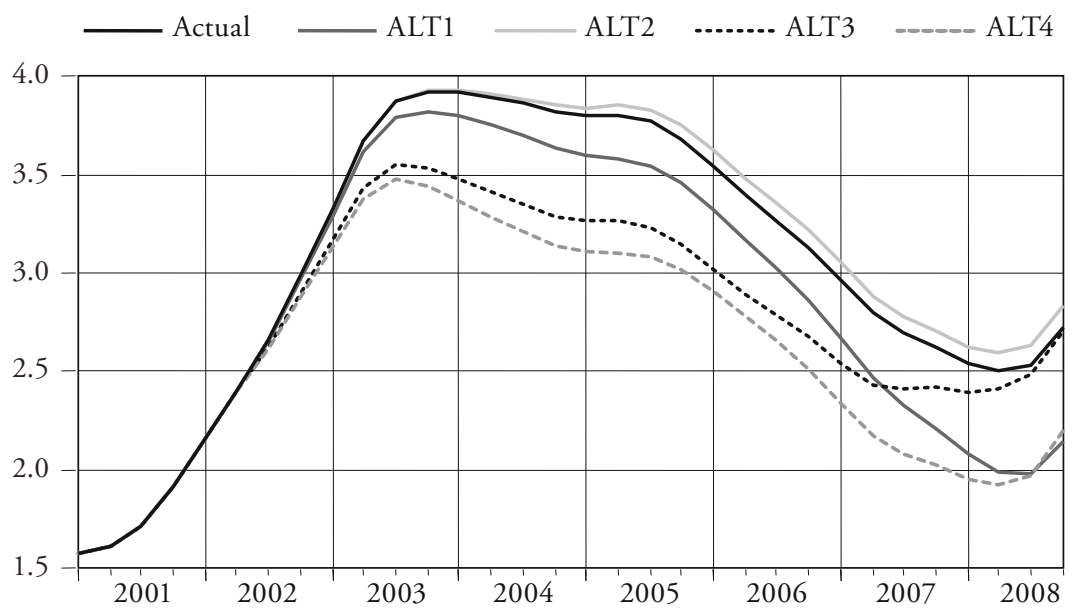


Figure 6 continued

e) GDP growth (y-on-y change in \%)

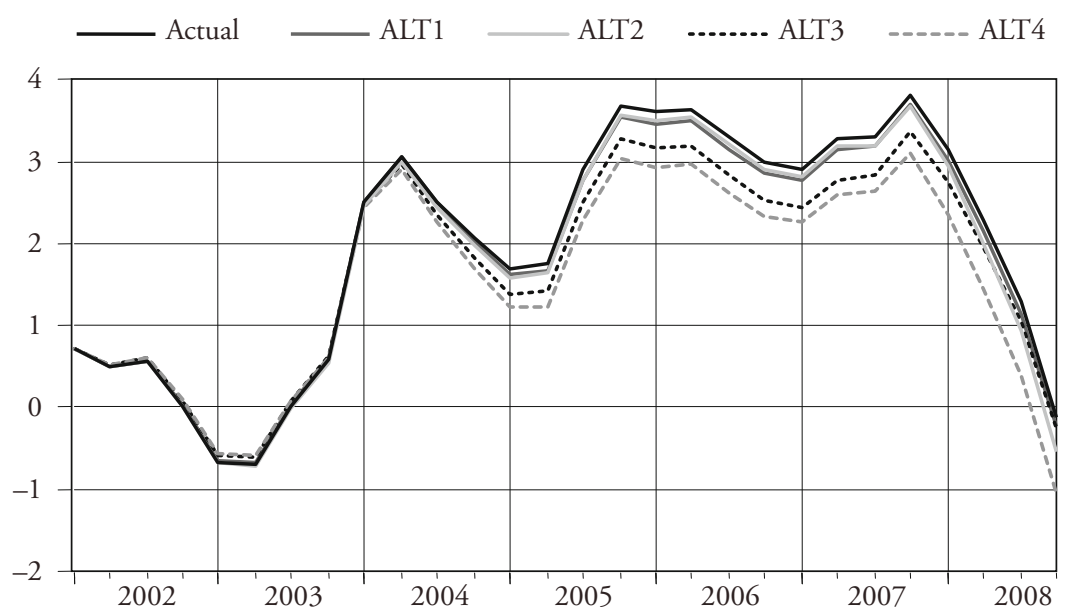

f) Inflation (GDP deflator) (y-on-y change in \%)

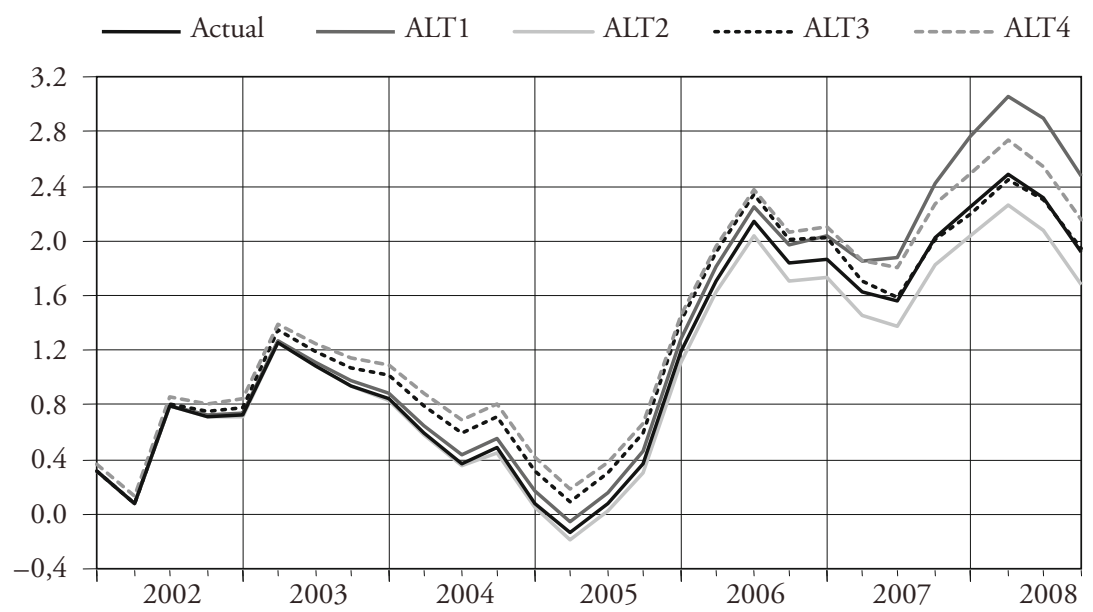


In simulation ALT3, the equation for $L_{-} T$ (temporary and cross-border workers) is reset to "status quo ante" behavior. As a result, the growth rate of $L_{-} T$ is reduced and falls to negative values in the high unemployment period 20032005. The above-mentioned substitution between $L F_{-} F$ and $L_{-} T$ now works in the opposite direction: Lower growth of $L_{-} T$ is partly compensated by higher growth of $L F \_F$. Nevertheless, the unemployment rate falls by about 0.5 percentage points below actual values. On the other hand, the reduced availability of foreign workers lowers GDP growth by 0.4 or 0.5 percentage points in 20052007, while inflation is lifted by about 0.2 percentage points. The effects identified by simulation ALT3 are relatively strong at the beginning of the simulation period but die out in 2007 and 2008. In contrast, the effects identified by simulation ALT1 and ALT2 become stronger in the course of the simulation period.

Simulation ALT4 includes all effects and interactions simultaneously. The simulation shows that under "status quo ante" conditions the unemployment rate would have risen by less in 2002-2003, peaking at 3.5\% instead of 3.9\%, and fallen more strongly to a trough of $1.9 \%$ in 2008 instead of $2.5 \%$, thus moving on a path that lies by 0.4 to 0.7 percentage points below actual values. Lower unemployment is the result of a reduced expansion of labor supply, counteracted to some extent by a weaker increase in labor demand. Reduced growth rates of both $L F_{-} F$ and $L_{-} T$ are responsible for the slower expansion of labor supply, while lower growth of $P O P_{-} F$ dampens labor demand via private consumption and housing investment from the demand side of the economy. Regarding GDP growth, the supply-side effects and the demand-side effects work in the same negative direction. GDP growth falls increasingly back in relation to actual values. The annual growth differences get as large at $0.9 \%$, amounting to a level difference of $3.2 \%$ at the end of the simulation period. In contrast, the individual effects on inflation are partly offsetting. The demandside effect resulting from lower population growth dampens inflation, whereas the supply-side effect resulting from reduced availability of foreign workers drives up inflation. The supply-side effect prevails, so that inflation as measured by the GDP deflator exceeds actual values by about 0.25 percentage points p.a. For CPI inflation, the difference is only 0.1 percentage points. One should note in this connection that monetary policy is tighter in the "status quo ante" simulation than is actually was; on the assumption of an identical policy course, inflation would increase by more under "status quo ante" conditions, as will be shown below.

Figure 7 confronts the actual development of nominal wages and consumer prices with the "status quo ante" simulation ALT4. In the absence of the migration agreement, the path of nominal wages would have steepened by more than 
the path of consumer prices. In 2008, the level difference over actual values reaches $2.4 \%$ for nominal wages and $0.7 \%$ for consumer prices, implying that the real consumer wage would have been $1.7 \%$ higher in 2008 in the absence of the migration agreement. This translates into an average annual gain in real wage growth of 0.25 percentage points under "status quo ante" conditions.

Figure 7: Impact of the Agreement on Wages and Prices

WAGE: Nominal wage index $2000=1$, CPI: Index $2000=1$

ALT4: Simulated "status quo ante" behavior

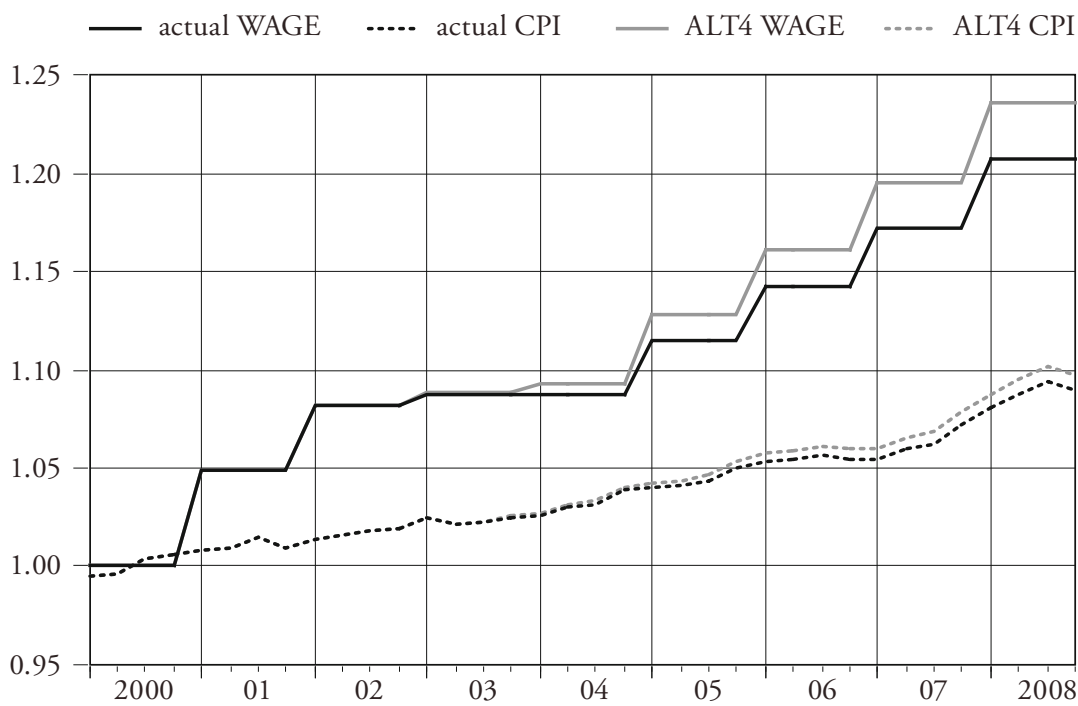

WAGE: Nominal wage index $2000=1$, CPI: Index $2000=1$, ALT4: Simulated "status quo ante" behavior

The preceding discussion was conducted in terms of deviations of the counterfactual "status quo ante" simulation from actual developments, as they took place under the migration agreement with the EU. Computed this way, the deviations show the effects of not having the migration agreement. Of course, one may reverse the comparison to obtain the effects due to the migration agreement. Expressed this way, the simulation results can be summarized as follows: 
- The migration agreement has significantly stimulated GDP growth. The level difference amounts to $3.2 \%$ in the course of the simulation period 2002-2008, corresponding to about 0.5 percentage points higher GDP growth p.a.

- With a cumulative effect of $2.8 \%$, the impact of the agreement on total employment was slightly weaker, so that there was a small positive impact on labor productivity.

- The effects of the agreement on inflation are weak ( 0.25 percentage points in terms of the GDP deflator, 0.1 percentage points in terms of consumer prices) because the dampening impact of increased labor supply was partly counteracted by a stronger expansion of aggregate demand. Aggregate demand was stimulated not only by higher population growth but also by monetary policy, which reacted to reduced inflationary pressures by pursuing a less restrictive course.

- As a dark spot in the picture, one must note that labor market developments were negatively affected by the migration agreement from the perspective of domestic wage earners: The unemployment rate was lifted by 0.5 to 0.7 percentage points above the path that would have resulted under hypothetical "status quo ante" conditions, and household suffered from a loss in real wage growth of 0.25 percentage points per year, amounting to a level difference of $1.7 \%$ in 2008 .

When interpreting the above simulation results, in particular the weak impact of the migration agreement on inflation, one has to keep in mind that monetary policy is endogenously determined in the model. In simulation ALT4, i.e. under hypothetical "status quo ante" conditions, the 3M-Libor follows a path that lies by roughly 0.5 percentage points above actual values, as shown in Figure 8a. Conversely expressed, the positive supply-side effects of the migration agreement allowed monetary policy to adopt a relatively lax stance, thus stimulating GDP growth from the demand side. Even so, inflation was slightly lower than it would have been in the absence of the agreement (Figure 8b). To isolate the effects of the agreement from the impact of monetary policy, one may keep the 3M-Libor on the actual path in a scenario ALT4x that otherwise corresponds to ALT4. As shown in Figure 8b, the relatively loose policy course, which was appropriate given the positive supply-side effects of the agreement, would have been inflationary in its absence. Inflation as measured by the GDP deflator (CPI inflation) would have increased to 5.7\% in 2007 (5.3\% in 2008). Hence, the implications of the migration agreement for inflationary pressures and monetary policy decisions are far from negligible. 
Figure 8: Monetary Policy Implications of the Agreement on Liberalized Migration

ALT4: Development without migration agreement

ALT4x: Development without migration agreement but actual course of 3M-Libor

a) $3 \mathrm{M}$-Libor in $\%$

actual

ALT4

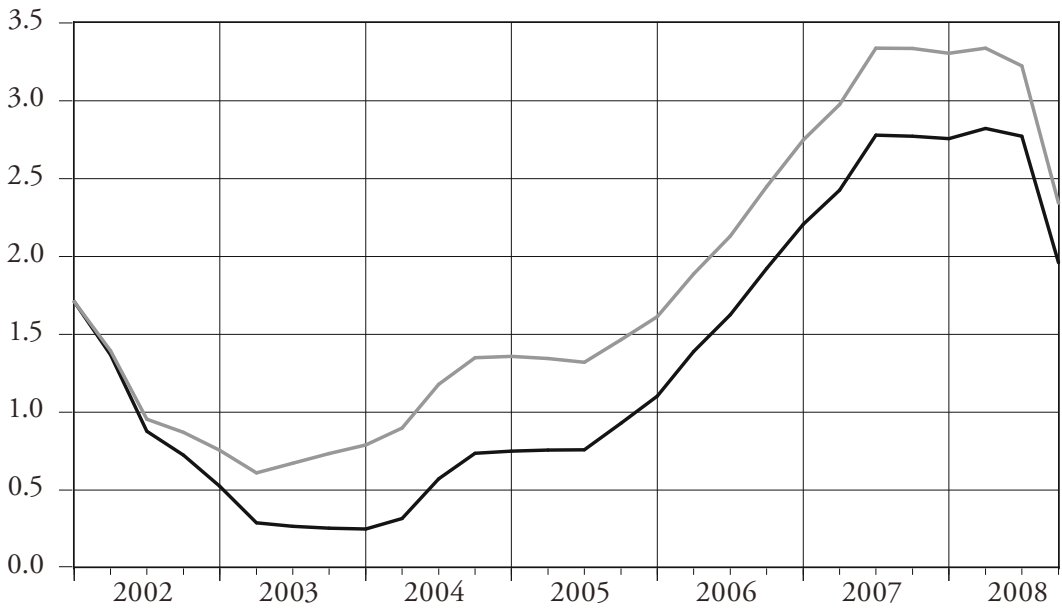

b) Inflation (GDP deflator)

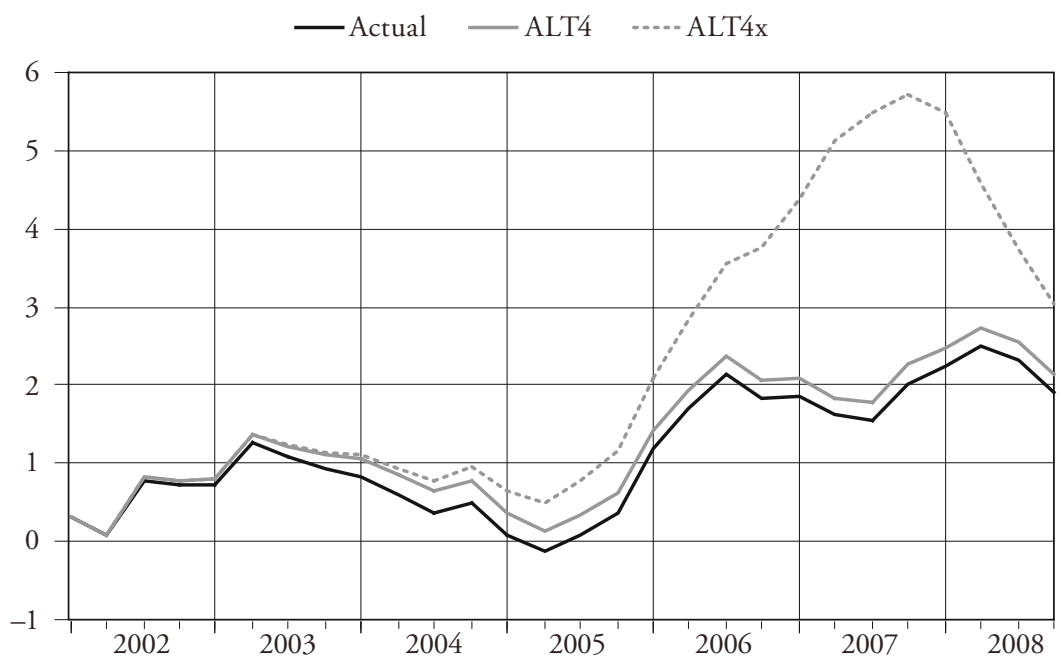




\subsection{Predicted Course of the Swiss Economy under Alternative Migration Dynamics}

This section tries to give an idea of the possible effects of the migration agreement over a full economic cycle. The analysis is carried out with reference to the forecasting situation encountered at the end of 2008. At that time, it became increasingly clear that the worldwide financial crisis would precipitate Switzerland into recession. Quarterly GDP growth rates had turned negative in the second half of 2008. Employment growth was still positive but dwindled strongly towards the end of 2008. Based on the assumption of an ongoing contraction of worldwide activity in 2009 and a relatively hesitant recovery thereafter, most observers of the Swiss economy predicted an extended period with negative GDP growth and - with a certain delay - a marked deterioration on the labor market. The unemployment rate, which had bottomed at $2.5 \%$ in $2008 \mathrm{q} 2$, was predicted to rise to peak values around $5 \%$ by mid-2010. Thereafter, GDP growth rates in excess of $2 \%$ were expected to bring about a gradual improvement on the labor market. In short, the forecasting situation at the beginning of 2009 was characterized by the prospect of a deepening recession, followed by a recovery that would reach the labor market towards the end of 2010.

This is by and large also the forecast scenario produced by the model of this paper. However, the outcome of the forecast and the corresponding monetary policy implications depend on fairly arbitrary assumptions about the macroeconomic effects of the migration agreement. The most critical point is whether the increased upward flexibility of labor supply observed in the upswing 20042008 is mirrored into increased downward flexibility in a recession. In case of such symmetry, the withdrawal of foreigners from the Swiss labor market would limit the rise in unemployment to the same extent as immigration has limited the fall in unemployment in the preceding upswing. On this assumption, the migration agreement would dampen the cyclical swings in unemployment but leave its long-term mean unaffected.

The data available thus far do not tell a clear story about the behavior of migration flows under the agreement in times of recession. Net-immigration amounted to about 80,000 additional foreign residents in 2009 . This represents a slowdown compared with the record net-immigration of 103,000 persons in 2008. On the other hand, net-immigration still proceeded at a rate that raised the number of foreign residents by nearly 5 percent and total population by one percent - despite declining employment and increasing unemployment. Stronger reactions to the deteriorating situation on the labor market can be observed for cross-border and temporary workers. After an increase from 175,000 in 2005 to 
213,000 by mid-2008, the number of cross-border workers has stagnated since then. Actually declining numbers can be observed for the small group of temporary workers (work permits up to one year); an increase from about 55,000 in 2005 to 70,000 at the beginning of 2007 was followed by a decrease to 45,000 towards the end of 2009. However, this decrease was not the result of a net-outflow from Switzerland but largely due to the fact that a significant number of temporary workers received long-term residence permits in this period. Hence, although the evidence is not watertight, it rather speaks against a symmetrically enhanced downward flexibility of foreign labor supply in times of recession. If the reaction is asymmetric, though, unemployment might rise over a full cycle due to kind of a "ratchet mechanism": In a downturn, unemployment rises strongly because the withdrawal of immigrants from labor supply is weak. In a subsequent upswing, rising labor demand quickly attracts an increasing number of new foreigners while the formerly dismissed workers (Swiss and old immigrants) remain in the unemployment pool.

The following forecast scenarios illustrate these different possibilities. The simulations run over the period 2009q1 to 2015q4 and are all based on the same world economy assumptions and the same model, except that different versions of equations (20), (21) and (22) are used:

- The SQA forecast is based on equations (20)-(22) in their "status quo ante" form, i.e. the parameter shifts that capture the impacts of the migration agreement are suppressed. This shows how somebody unaware of the behavioral changes caused by the agreement might predict the course of the Swiss economy. A difficulty in the design of this scenario resides in the fact that the migration agreement has already affected the Swiss economy prior to the forecast period. In particular, the levels of the three variables $L_{-} T$ (temporary and cross-border workers), $L F \_F$ (foreign potential labor force) and POP_F (foreign resident population) were higher at the end of 2008 than they would have been in the absence of the agreement. Computing a forecast in which the Swiss economy reverts to a "status quo ante" situation as if the agreement had never been concluded does not make sense. The effects of the agreement that took place until the end of 2008 should rather be regarded as "sunk" and the model reset to "status quo ante" conditions only as far as the behavior of immigration in the forecast period is concerned. In equations (21) and (22) this happens automatically since the variables $L F_{-} F$ and $P O P_{-} F$ appear only in form of first and second differences. Equation (20) in contrast involves in its error-correction term the level of $L_{-} T$. In order to make the "status quo ante" version of this equation compatible with the elevated level of $L_{-} T$ at the 
starting point of the forecast, the constant term $\beta_{0}$ must be adjusted accordingly. The SQA forecast serves as a reference path to which the following two forecast scenarios can be compared.

- The SYM forecast uses equations (20)-(22) with all shifts in the slope parameters, implying that the enhanced reactions of $L_{-} T, L F_{-} F$ and $P O P_{-} F$ to changing labor market conditions apply symmetrically both in upswings and downturns.

- The ASYM Forecast assumes that reactions in the three variables are strengthened by the migration agreement only in upswings whereas the equations are set to "status quo ante" behavior in downturns. This gives rise to the abovementioned "ratchet effect" in the development of unemployment. Technically, the asymmetry is modeled by setting the dummy variables that switch on/off the parameter shifts to one (zero) if the proportion $\pi_{L}$ of labor-constrained firms increases (decreases).

Figure 9 shows the outcome of the exercise for some key variables of the model. First, we compare the SQA forecast with the SYM forecast. In the SQA forecast, the unemployment rate increases from $2.5 \%$ in 2008 to a maximum of $5.2 \%$ by mid-2010, falls back to $2.5 \%$ in 2012 and rises again to $4.1 \%$ in 2014 . In the SYM forecast, the swings in unemployment are smaller due to stronger procyclical reactions in the foreign work force. The unemployment rate increases to a maximum of $4.5 \%$ instead of $5.2 \%$ as the deteriorating situation on the labor market lowers the growth rate in the foreign labor force from $4 \%$ in 2008 to $1.3 \%$ in 2010 . Reduced immigration also affects aggregate demand, mainly via private consumption and housing investment. As a result, GDP growth falls short of the SQA forecast, which in turn lowers labor demand. However, since the downward adjustment in labor supply resulting from reduced immigration is more pronounced, unemployment increases by less. In the subsequent upswing, the reverse happens: Falling unemployment and an increasing share of laborconstrained firms drive the growth rate in the foreign labor force up to $3.5 \%$, which mitigates the decline in unemployment. The unemployment rate falls to a minimum of $3.0 \%$, compared with $2.5 \%$ in the SQA forecast.

As the supply-side effects of immigration prevail over the demand-side effects, stronger reactions to labor market conditions also attenuate the swings in inflation in the SYM forecast. In the SQA forecast, CPI inflation increases - with a short lag on falling unemployment - from $0.5 \%$ in $2011 \mathrm{q} 1$ to $2.1 \%$ in $2012 \mathrm{q} 4$. In the SYM forecast, the respective numbers are $0.6 \%$ and $1.6 \%$. 
Figure 9: Impacts of the Migration Agreement on Forecast 2009-2015

SQA: "Status quo ante": Parameter shifts in eqs. (20)-(22) suppressed

SYM: Enhanced reactions of migration to labor market tension in downturns and upturns ASYM: Enhanced reactions of migration to labor market tension only in upturns

a) Foreign Potential Labor Force (q-on-q change in \%)

-SQA —SYM -.-- ASYM

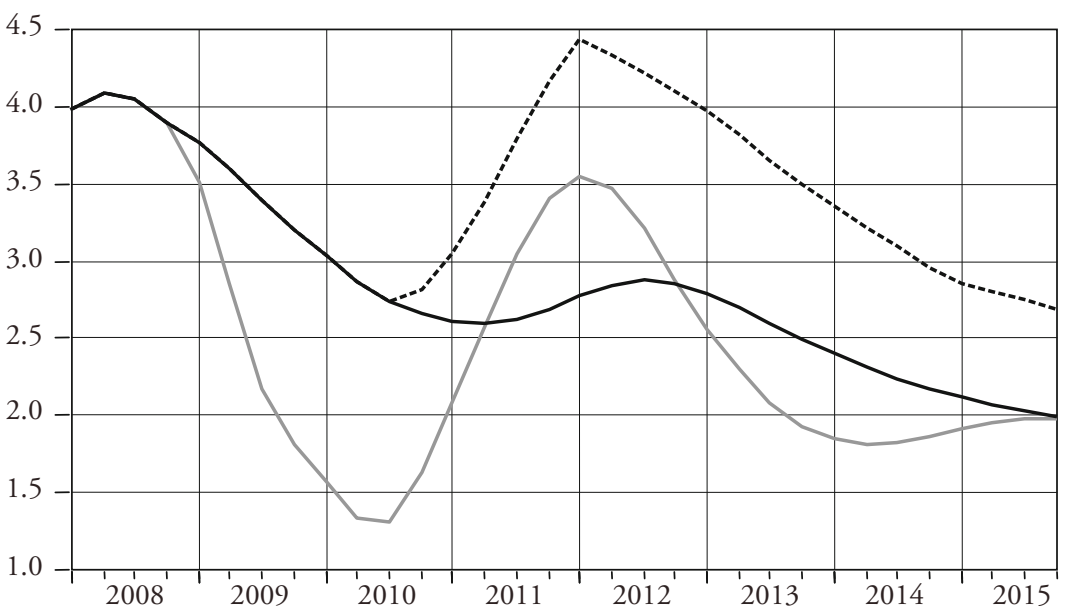

b) Temporary and Cross-Border Workers (q-on-q change in \%)

-SQA —SYM -.-. ASYM

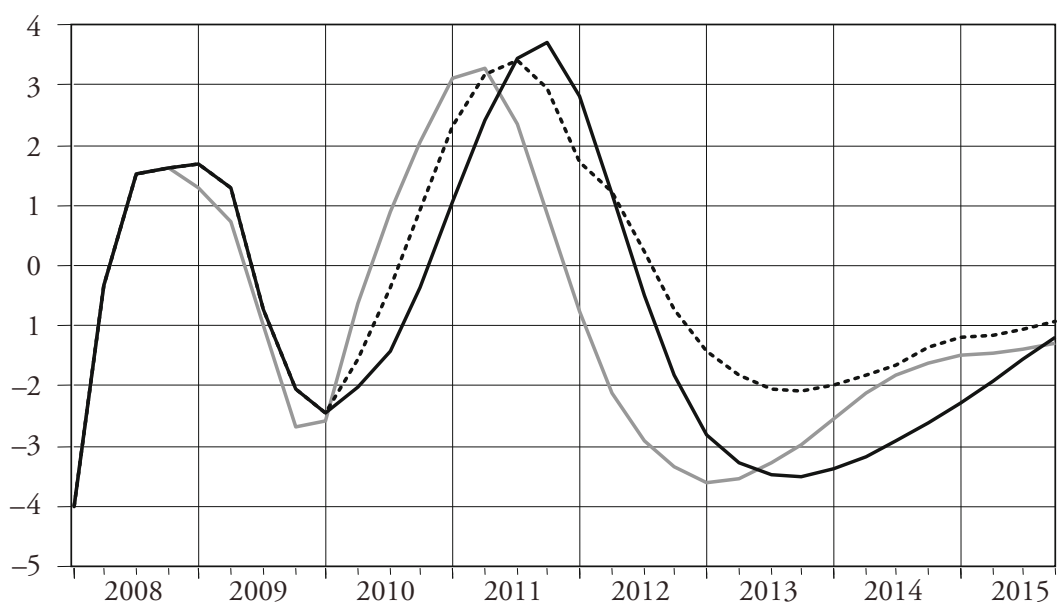


Figure 9 continued

c) Unemployment Rate (in \%)

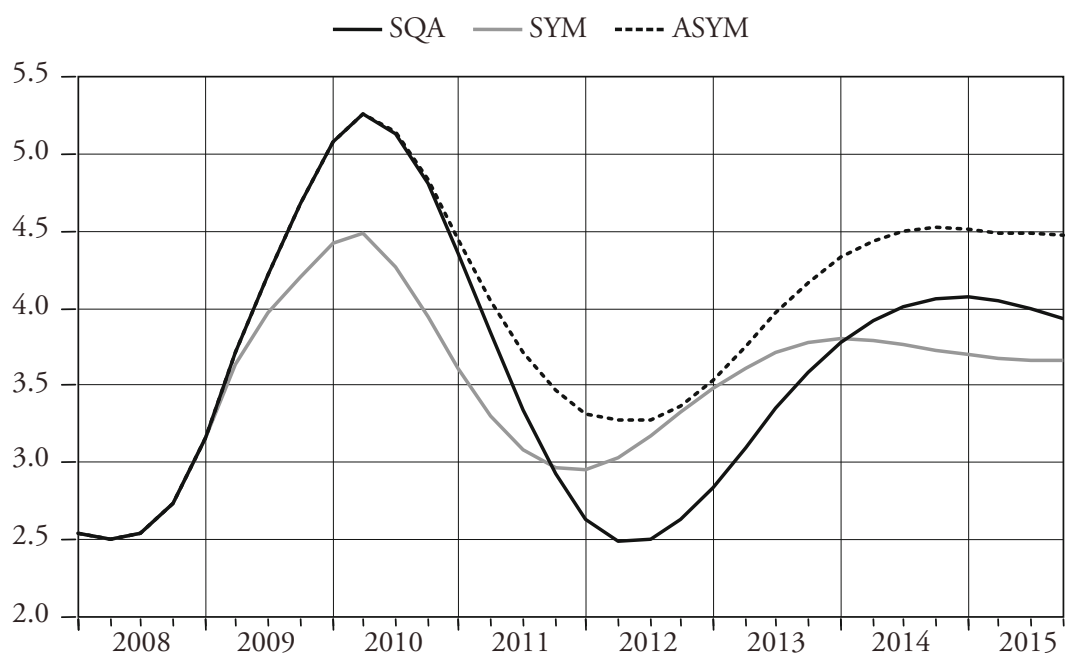

d) GDP Growth (q-on-q change in \%)

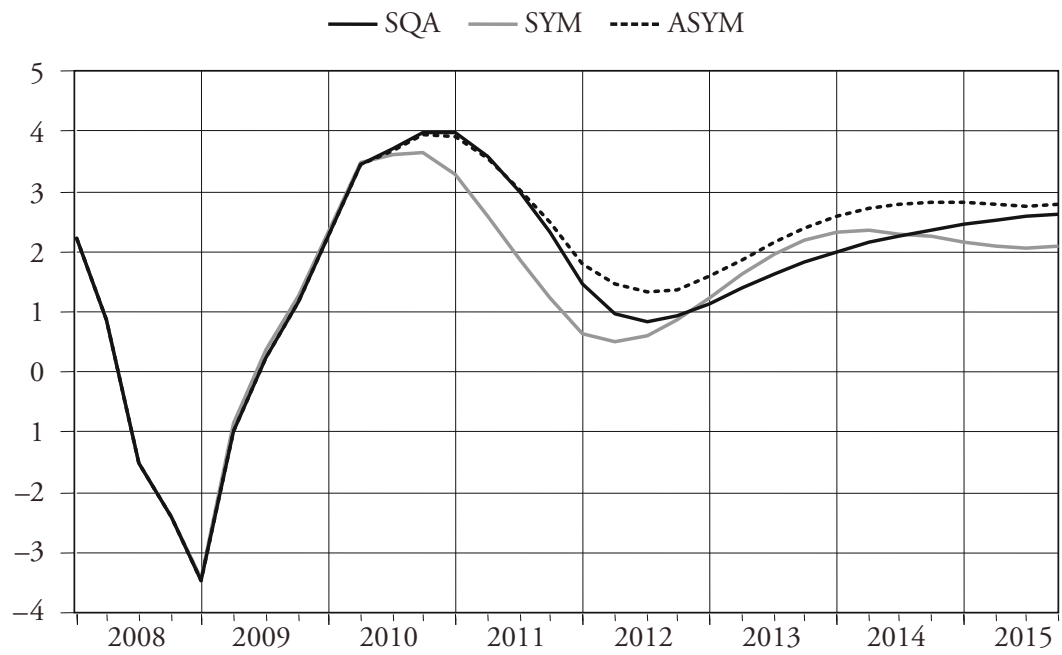


Figure 9 continued

e) Share of labor-constrained firms

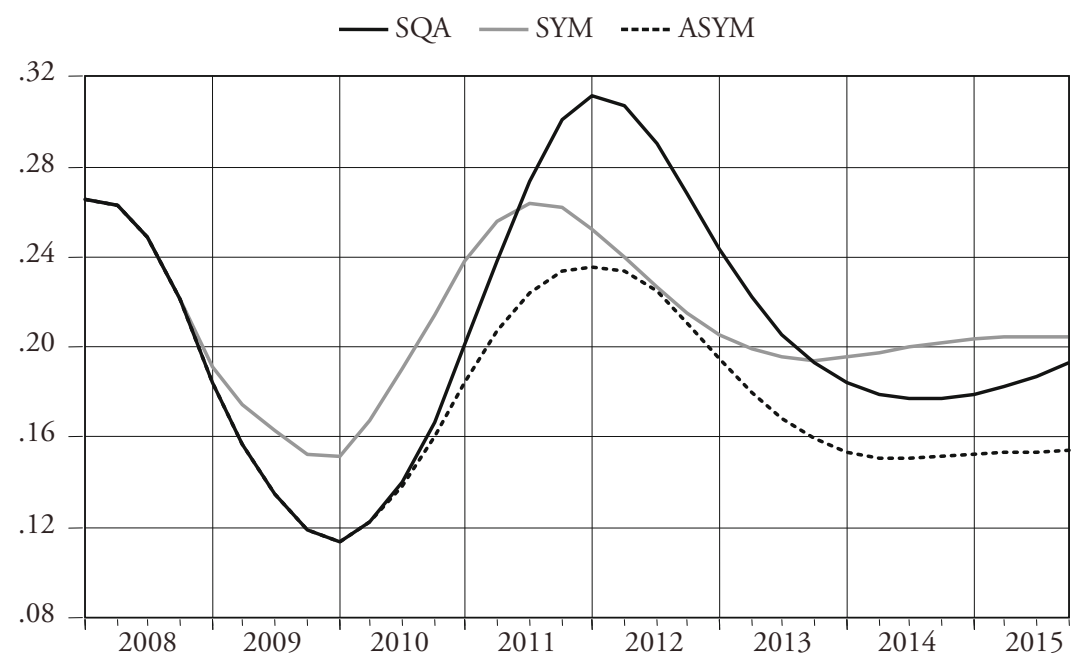

f) CPI inflation (y-on-y change in \%)

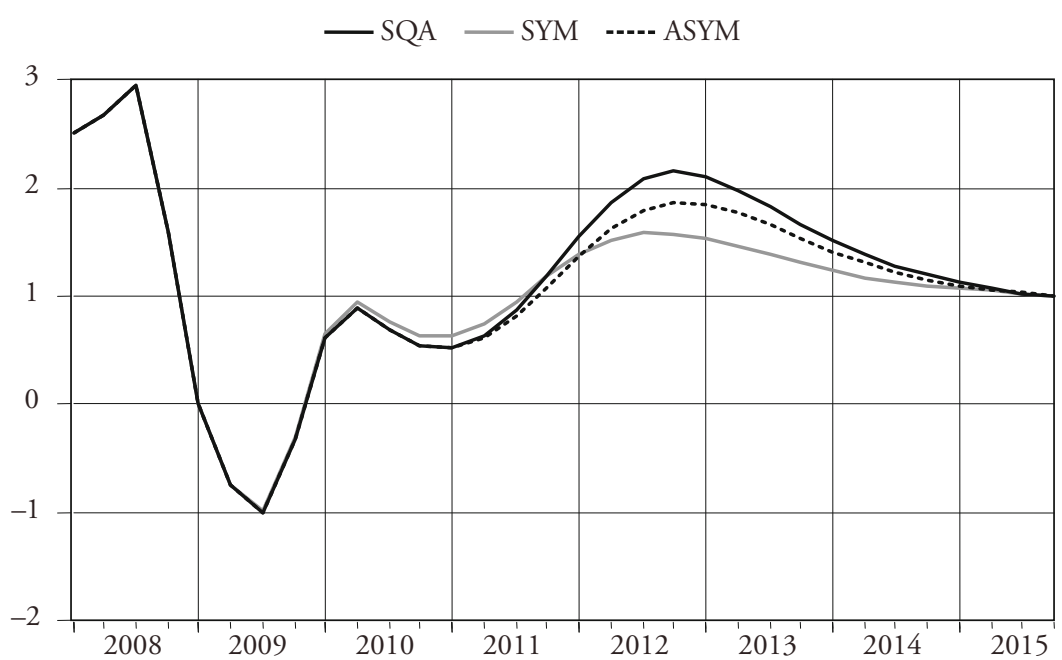


In short, the SYM forecast differs from the SQA forecast in that more pronounced pro-cyclical movements in the foreign labor force reinforce the cyclical swings in GDP growth and employment but dampen the cyclical swings in unemployment and inflation. However, the underlying assumption of symmetrically enhanced reactions of immigration to changing labor market conditions may be unrealistic. Considering the empirical evidence available so far, asymmetric effects in the sense of strengthened reactions in an upturn but unchanged reactions in a downturn cannot be excluded. The ASYM forecast, which is presented next, allows for such an asymmetry.

In the first six quarters of the forecast period (2009q1-2010q2), the ASYM forecast coincides with the SQA forecast because the labor market situation worsens and equations (20)-(22) are accordingly set to "status quo ante" behavior. Small differences between the SQA and the ASYM forecast might show up because monetary policy is forward-looking and therefore influenced by developments later in the forecast period. However, since the $3 \mathrm{M}$-Libor is constrained by the lower bound - assumed to be $0.3 \%$ - in both forecasts until $2010 \mathrm{q} 3$, they are exactly identical over the first six quarters of the forecast period. As shown in Figure 9, the growth rate of the foreign labor force falls only slightly during this period and the unemployment rate increases to $5.2 \%$. In the subsequent upturn, immigration is assumed to react strongly to the improving labor market situation (comparable to the upswing 2005-2008), to the effect unemployment remains relatively elevated despite the marked recovery of labor demand. The unemployment rate falls to a local minimum of $3.3 \%$ in 2012 , compared with $2.5 \%$ in the SQA forecast and $3.0 \%$ in the SYM forecast. Thereafter, the situation on the labor market worsens again and the reaction of immigration is accordingly reset to "status quo ante" behavior. As a result, the unemployment rate increases markedly. It stabilizes around $4.5 \%$ in 2014-2015, whereas it tends to values between $3.5 \%$ and $4 \%$ in the SYM and SQA forecasts.

Due to the asymmetric reaction of immigration in downturns and upturns, the ASYM forecast is the most expansive one with respect to population growth over a full economic cycle. This also carries over to GDP growth, which is stimulated by immigration both from the supply side and the demand side. Average GDP growth over the entire forecast period 2009q1 to 2015q4 is $2.1 \%$ in ASYM, compared with $1.9 \%$ in SQA and $1.7 \%$ in SYM. Average growth rates of GDP per hour worked (labor productivity) in contrast are practically identical in the three forecasts around $1.1 \%$. The comparatively high GDP growth rates in the ASYM forecast entail a temporary scarcity of technical production capacities, reflected in a relatively large share $\pi_{G}$ of capacity-constrained firms. Therefore, inflation in 2012 and 2013 runs above the SYM forecast (even though the share 
$\pi_{L}$ of labor-constrained firms is relatively low) but below the SQA forecast (where both $\pi_{L}$ and $\pi_{G}$ are relatively high). ${ }^{6}$

According to equation (20), the reaction of temporary and cross-border workers $\left(L_{-} T\right)$ to changing labor market tension as measured by $\pi_{L}$ is also enhanced by the migration agreement. However, as can be seen from Figure 9b, the swings $L_{-} T$ in the SYM and ASYM forecast are hardly more pronounced than in the SQA forecast. Why? First, stronger reactions of $L_{-} T$ to $\pi_{L}$ feed back in a stabilizing way on $\pi_{L}$. Second, the behavior of the residential foreign labor force $\left(L F_{-} F\right)$ has a stabilizing impact on $\pi_{L}$ as well. The swings in $\pi_{L}$ in the SYM and ASYM forecast are therefore smaller than those in the SQA forecast. Hence, despite bigger reaction coefficients, the number of temporary and cross-border workers does not fluctuate more strongly in the SYM and ASYM forecast. One should note in this connection that temporary and cross-border workers account for only $7 \%$ of total employment whereas the share of foreigners in the residential labor force is $25 \%$. Differences between the SQA, SYM and ASYM forecasts are thus mainly due to differences in the behavior of workers with residence status while the role of temporary and cross-border workers is rather reactive.

What are the differences between the scenarios SQA, SYM and ASYM in terms of wage developments? The three scenarios differ more strongly for wages than for prices. Due to the assumed retreat of foreigners from a deteriorating Swiss labor market, the level of nominal wages is first highest in the SYM forecast but falls below the SQA path in the upswing from mid-2012 onwards as the inflow of new immigrants thwarts the fall in unemployment. The nominal wage loss in the SYM forecast is accompanied though by a nearly proportionate decline in consumer prices so that the real wage in 2015 is practically the same as in the SQA forecast. Less favorable from the perspective of domestic wage earners is the ASYM scenario because former immigrants do not leave the country in the period of labor market weakness (in contrast to SYM) but new immigrants are attracted in the following upswing (in contrast to SQA). As a result, nominal wages in the ASYM forecast are $1.8 \%$ below the SQA forecast in 2015. Corrected for the difference in consumer prices, the real wage loss is $1.2 \%$.

As mentioned above, monetary policy is endogenously determined in the three forecast scenarios. The policy rule for the $3 \mathrm{M}$-Libor is forward-looking and steers CPI inflation to a target of one percent in 2015 in all three scenarios (see Figure 9f). Differences in inflationary pressure thus show up only temporarily but

6 As explained in Section 2.2, inflation is driven both by tension in the labor market (high $\pi_{L}$ drives up wages in relation to prices) and tension in the goods market (high $\pi_{G}$ drives up prices in relation to wage costs). 
are fully absorbed by monetary policy reactions in the longer run. In the first six quarters of the forecast period, when unemployment is increasing and inflation low or even negative, monetary policy keeps the 3M-Libor at the lower bound of $0.3 \%$ both in the SQA and the ASYM forecast, as shown in Figure 10a. In the SYM forecast, where the retreat of foreigners mitigates the increase in unemployment, monetary policy is tightened one quarter earlier. In 2011q1, the 3M-Libor is already at $2.1 \%$ in the SYM forecast, compared with $1.3 \%$ in the ASYM forecast and $1.2 \%$ in the SQA forecast. In the following quarters, the 3M-Libor moves highest in the SQA scenario because the relatively strong fall in unemployment exerts upward pressure on inflation. In 2012q2, the 3M-Libor is at 3.2\%, compared with $2.8 \%$ in both the ASYM and SYM forecast. Hence, in order to have inflation at $1 \%$ in 2015 , fairly different monetary policy courses are required, depending on the assumed behavior of migration flows.

Another way to highlight the monetary policy implications of the migration agreement is to condition the SYM and ASYM forecast on the path of the $3 \mathrm{M}$-Libor that steers inflation to $1 \%$ in the SQA scenario. The resulting inflation forecasts are shown in Figure 10b. Again, the SYM and SQA forecasts do not differ much, except for a somewhat dampened cyclicality of inflation in the SYM forecast. However, if monetary policy is conducted in a way consistent with an inflation target of $1 \%$ under "status quo ante" conditions but the economy actually behaves according to the ASYM scenario, then inflation undershoots the target by 0.4 percentage points.

\section{Conclusion}

In recent years, increasing inflows of foreign workers into many Western countries have revived interest in the effects of migration on wages, the wage distribution, employment and unemployment. For a review of the vast literature emerging from this research effort, see e.g. Ottaviano and Perry (2008) or OKKerese (2008). When analyzing the effects of immigration, a useful theoretical starting point is to assume a constant-returns-to-scale production function with different types of labor and a perfectly elastic supply of capital. On these assumptions, an inflow of immigrants with the same skill-mix as the native population does not alter relative wages for different skill groups, leaves labor productivity and the aggregate real wage unchanged and also has no impact on the unemployment rate. It just "blows up" the entire economy by a scale factor in proportion to raising labor supply. What happens in reality can then be discussed in the form of deviations from this theoretical benchmark situation. 
Figure 10: Monetary Policy Implications of Migration Agreement in Forecast 2009-2015

SQA: "Status quo ante" forecast (parameter shifts in eqs. (20)-(22) suppressed)

SYM: Enhanced reactions of migration to labor market tension in downturns and upturns ASYM: Enhanced reactions of migration to labor market tension in upturns only

a) $3 \mathrm{M}$-Libor in $\%$ (steering CPI inflation to $1 \%$ in 2015 )

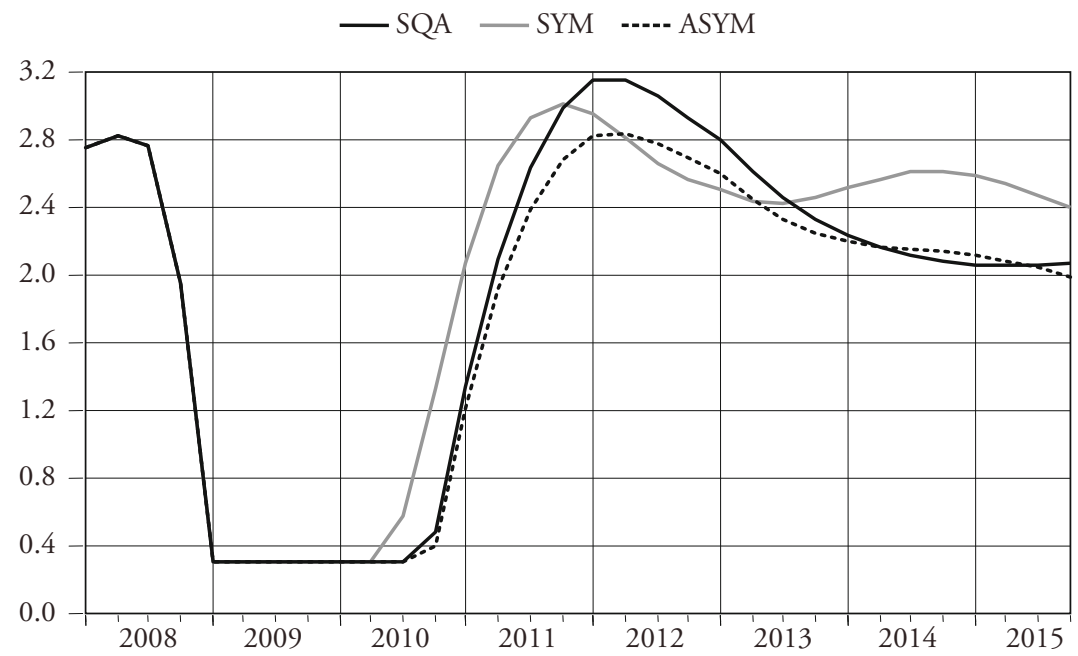

b) CPI Inflation (under SQA-path for 3M-Libor)

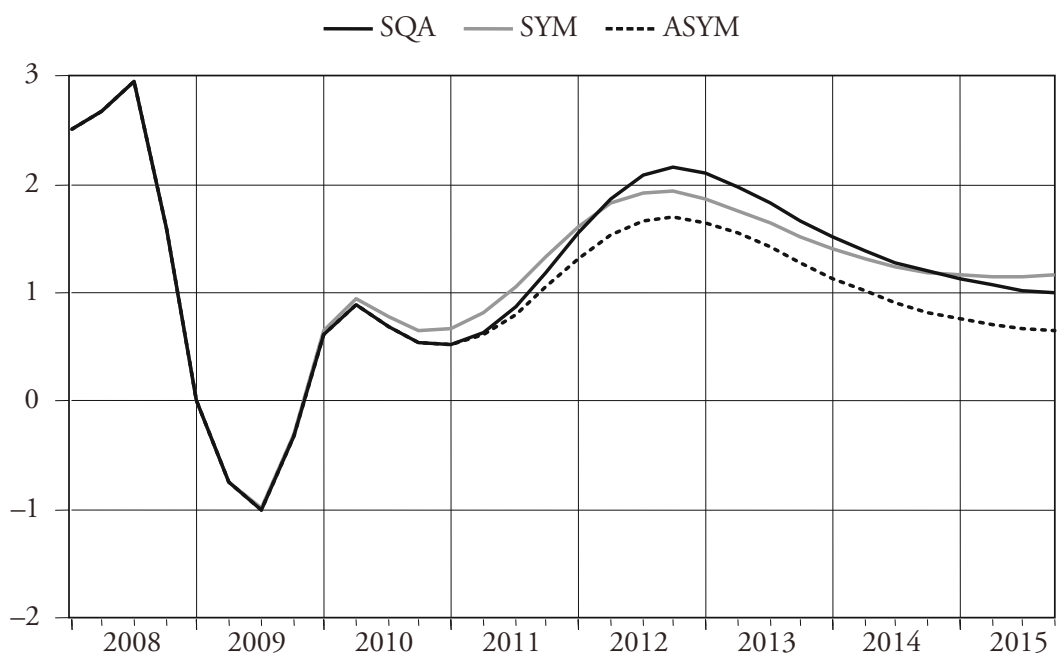


First, the skill-mix of new immigrants typically differs from the skill-mix of those already residing in the country (natives and old immigrants). Therefore, immigration will impact on the wage distribution. Relative wages for skills that become relatively more (less) abundant will fall (rise). Second, the adjustment of the physical capital stock to a growing work force may take place with some delay, so that immigration temporarily raises unemployment and lowers labor productivity and real wages. Deviations from the benchmark case may also result from the fact that land, housing and certain parts of the public infrastructure are factors that cannot easily be enlarged in step with an increasing work force. Immigrants may furthermore differ from the residential population with respect to consumer behavior.

The majority of recent research has focused on differences in the skill-mix between new immigrants and the resident population. One strand of research, mostly in application to the US labor market, relates differences in labor market outcomes (wages, unemployment) in cross-section regressions to the uneven geographical distribution of immigrants. Early studies of this kind, which mostly found only small effects of immigrants on wages and employment perspectives of natives, were criticized for two reasons. First, if immigrants are endogenously attracted to regions with relatively tight labor markets, the resulting correlation between the shares of immigrants and local wages might be positive even if immigration has actually a wage-dampening effect in these markets. Second, if immigration lowers local wages and/or raises unemployment, an outflow of natives from such areas may diffuse the effects throughout the economy so that not much is left to be measured in a cross-region regression.

Subsequent work has reacted to this criticism by reverting to instrumental variable estimation, see e.g. Pischke and Velling (1997), Winter-Ebmer and Zweimüller (1999) and Angrist and Kugler (2003). Other authors like Card (1990) and FrIEDbERG (2001) circumvented the endogeneity problem by looking at historical episodes in which the inflow of migrants was clearly caused by exogenous political factors. Regarding the outflow of natives from high-immigration areas, BorJas (2005) pointed out that this behavior is empirically relevant and significantly blurs the impact of immigration on wages identified in cross-section regressions. In another paper, Borjas stresses the importance of measuring skills not only in terms of formal educational attainment but also in terms of work experience because immigrants and natives differ strongly in this respect (BORJAs, 2003). On this basis, he finds that an immigration inflow which raises the number of workers in a certain skill group by 10 percent reduces earnings in this skill group by 4 to 6 percent. The effect is notably stronger than the effects usually reported in studies that do not account for work experience. 
Several authors, including Borjas (2003), Manacorda et al. (2006), D'Amuri et al. (2008), Оttaviano and Perry (2008) and Aydemir and Borjas (2007), have analyzed the effects of immigration on relative wages by estimating substitution elasticities between different types of labor in the framework of multilevel CES production functions. This structural approach is attractive because it identifies not only the negative impact of immigrants on wages of competing workers but also the effects on wages of workers who are complements and therefore may benefit from immigration. On the other hand, the approach relies heavily on theoretical assumptions that are not thoroughly checked empirically. In particular, equating the impacts of immigration on the marginal products of different types of labor directly with changes in the wage distribution is rather daring. Moreover, the wage-damping effect of immigration is inversely related to the rather arbitrarily assumed adjustment speed of capital. According to BoRJAS (2003), the influx of immigrants into the US in the 1980s and 1990s lowered average wages by 3.2 percent, with larger effects at the bottom and the top of the skill distribution. However, this result is conditional on the assumption of a constant capital stock and an elasticity of substitution between aggregate labor and capital of one. In a study for Switzerland, SHELdon (2003) argues that foreign and domestic workers are only weak substitutes so that a one percent increase in immigrant employment lowers wages of Swiss workers by 0.1 to 0.3 percent only. Overall, as noted in the meta-analysis of LoNGHI et al. (2005), most studies find only moderate detrimental effects of immigration on wages and job opportunities of natives. This is also the result of a recent study for Switzerland (GERFIN and KAISER, 2010); the recent inflow of foreigners with higher education has narrowed the wage distribution across skill groups with only a weak negative impact on the average real wage.

This short review of recent immigration studies is certainly not exhaustive. What it clearly demonstrates, however, is the microeconomic focus of recent research. As immigrants and natives differ with respect to education and work experience, it was considered important to disaggregate labor into many skill groups and to determine whether they act as substitutes or complements in production. Depending on the outcome, immigration of a particular type of labor may raise or lower relative wages and employment of natives in a certain skill group. What is usually missing from this type of analysis, though, is the time dimension and in particular the dynamics of capital accumulation. The identified effects - typically derived from cross-section regressions - are either interpreted as long-run effects on the (implicit) assumption that the capital stock fully adjusts to changes in the work force, or they are viewed as short-run effects on the proviso of an unchanged capital stock. Moreover, the studies are usually 
confined to the labor market. The role of immigrants as consumers and tenants is not taken into account, and the impacts of lower wage costs on inflation, interest rates and the competitiveness of different industries in international trade are also not investigated.

Compared with this literature, the present paper on the one hand looks simplistic because no distinction is made between different types of labor. On the other hand, it seeks to analyze immigration in a macroeconomic and dynamic context, including the interplay with private consumption, housing construction, wageprice dynamics, profitability of new investment, international trade and monetary policy. In other words, the focus of the paper is not on how a (hopefully) exogenous inflow of immigrants affects wages and job opportunities of natives but rather to what extent the functioning of the entire economy changes when restrictions on immigration are abolished in favor of an almost complete opening of the labor market to foreign competition. In this analysis, immigration is an intrinsically endogenous variable and, as such, likely to alter the cyclical and long-run behavior of the economy. Keeping track of such changes is important, not least from the viewpoint of monetary policy. For example, facilitated immigration is likely to reduce the incidence of labor shortages and thus exert a dampening effect on inflation in economic upturns. However, the influx of migrants at the same time affects the demand side of the economy by raising consumption, housing investment and - to the extent that immigration eliminates labor bottlenecks - firms' investment in plant and equipment. Therefore, it is theoretically unclear whether facilitated immigration actually reduces inflationary pressures. Moreover, the question arises whether the increased upward flexibility of labor supply in an upswing is symmetrically mirrored into increased downward flexibility in a recession. Macroeconomic key figures that are important for the conduct of monetary policy like equilibrium unemployment and potential output growth may also be affected by the enhanced availability of personnel.

The analysis of this paper addresses these issues in the framework of an existing econometric model for Switzerland. The model has proved useful as a forecasting and simulation tool for many years. One may therefore be fairly confident that it captures the historical interplay of macroeconomic variables in an appropriate way. The question to be asked against this background is whether this still holds true under the new migration agreement with the European Union. This question is not easy to deal with empirically because the experiences with the new regime are short and largely pertain to a period characterized by a sustained upswing (2004-2008). Nevertheless, by checking the critical equations of the model for parameter shifts, it was possible to identify three channels through which the migration agreement affected the Swiss economy: First, under the new regime, 
excess demand for labor raised the growth rate of foreigners with residence permits more quickly. Second, shortages in the Swiss labor market also attracted larger numbers of cross-border and temporary workers (work permits up to one year). These two effects give rise to increased upward flexibility of labor supply in upswings, mitigate the incidence of labor shortages, dampen inflation and give leeway to higher GDP growth from the supply side. Third, the new immigration regime has also affected the demand side of the economy: Along with the stronger reaction of the foreign labor force, foreign population rose more quickly in the recent upturn as well. This stimulated GDP growth from the demand side and thereby counteracted the inflation dampening supply-side effect of immigration to a fairly large extent.

In some more detail, the main findings of the study can be summarized as follows. The migration agreement has stimulated GDP growth. Compared with a counterfactual "status quo ante" simulation, the annual growth differences get as large at $0.9 \%$, amounting to a level difference of $3.2 \%$ over the entire simulation period 2002-2008. With a cumulative effect of $2.8 \%$, the impact of the agreement on employment was somewhat weaker, implying that labor productivity was slightly raised. Annual inflation was lowered by 0.25 percentage points on average in terms of the GDP deflator and only 0.1 percentage points in terms of consumer prices. These effects are small since the increased growth potential was largely absorbed by a stronger expansion of aggregate demand due to higher population growth. Aggregate demand was further stimulated by monetary policy, which reacted to reduced inflationary pressures by pursuing a less restrictive course. When the monetary reaction is suppressed, the inflation dampening impact gets stronger, of course at the cost of a smaller stimulation of GDP growth (and thus weaker immigration). On the other hand, the relatively loose actual course of monetary policy would have been inflationary in the absence of the positive supply side effects of the migration agreement. CPI Inflation would have increased to $5.3 \%$ in 2008 . Hence, the implications of the new migration regime for monetary policy are quite substantial.

On the negative side, one has to note that the widely expected gains in labor productivity turned out to be disappointingly weak. Moreover, labor market developments were negatively affected from the perspective of the residential population: The unemployment rate was lifted by 0.5 to 0.7 percentage points above the path that would have resulted under hypothetical "status quo ante" conditions, and households suffered from a loss in annual real wage growth of 0.25 percentage points on average, amounting to a level difference of $1.7 \%$ by 2008 .

In a final paragraph, the paper tries to figure out the implications of the migration agreement over a full economic cycle. This undertaking is rather speculative 
since it is unclear at the moment whether the increased upward flexibility of foreign labor force observed in the preceding upswing will be mirrored into increased downward flexibility in a recession. If such symmetry holds, the migration agreement reinforces the cyclical swings in GDP growth and employment (both from the supply and the demand side) but dampens the cyclical swings in unemployment and inflation (because the supply-side effects of immigration exceed the demand-side effects) while leaving the long-term averages unaffected. In contrast, if the reaction of migration flows to rising and falling labor demand is asymmetric, unemployment is likely to increase over a full economic cycle due to a "ratchet mechanism": In a downturn, unemployment rises strongly because the withdrawal of immigrants from labor supply is relatively weak. In a subsequent upswing, however, recovering labor demand quickly attracts an increasing number of foreigners while the formerly dismissed workers remain in the unemployment pool. In this scenario, higher unemployment exerts a dampening impact on the development of real wages and inflation. Monetary policy accordingly follows a relatively expansionary course.

These different possibilities are illustrated in the paper by means of model simulations. Unfortunately, the realism of the scenarios it is difficult to assess at the moment. On the one hand, the influx of foreigners has declined in 2009. On the other hand, net-immigration was still positive at a rate that appears rather high in view of declining employment and increasing unemployment. Hence, although the evidence is by no means watertight, it is arguably in better accordance with the view that migrants are more easily attracted to Switzerland in upswings than they tend to leave the country in downturns. If one shares this view, one should be careful not to view the asymmetry as being fully rooted in the behavior of foreigners. It has probably much more to do with the behavior of firms: In a recession, they sack workers who are not ideally qualified for their jobs (Swiss and previous immigrants). In a subsequent upswing, however, they do not re-hire those workers but look for better qualified and motivated new applicants abroad. In the longer run, this behavior would enhance the quality of the work force, at the cost though of higher equilibrium unemployment and a growing number of long-term unemployed. 


\section{References}

Angrist, J. and A. Kugler (2003), "Protective or Counter-Productive? Labour Market Institutions and the Effect of Immigration on EU Natives", Economic Journal, 113, pp. 302-331.

Aydemir, A. and G. Borjas (2007), "Cross-Country Variation in the Impact of International Migration: Canada, Mexico, and the United States", Journal of the European Economic Association, 5, pp. 663-708.

Borjas, G. (2003), "The Labor Demand Curve is Downward Sloping: Reexamining the Impact of Immigration on the Labor Market", Quarterly Journal of Economics, 118, pp. 1335-1374.

Borjas, G. (2005), "Native Internal Migration and the Labor Market Impact of Immigration", NBER Working Paper 11610.

CARD, D. (1990), "The Impact of the Mariel Boat Lift on the Miami Labor Market", Industrial and Labor Relations Review, 43 (2), pp. 245-257.

CARD, D. (2005), "Is the New Immigration Really So Bad?", Economic Journal, 115, F300-F323.

D’Amuri, F., G. I. P. Ottaviano and G. Peri (2008), “The Labor Market Impact of Immigration in Western Germany in the 1990's", NBER Working Paper 13851.

Drèze, J. H. and Ch. Bean (1990), Europe's Unemployment Problem, MIT Press, Cambridge.

FriedberG, R. M. (2001), "The Impact of Mass Migration on the Israeli Labor Market”, Quarterly Journal of Economics, 116, pp. 1373-1408.

Gerfin, M. and B. Kaiser (2010), "The Effects of Immigration on Wages in Switzerland”, working paper, Departement Volkswirtschaftslehre, Universität Bern.

Lambert, J. P. (1988), Disequilibrium Macro Models, Theory and Estimation for Rationing Models Using Business Survey Data, Cambridge University Press, Cambridge.

Layard, R., S. Nickel and R. Jackman (1991), Unemployment, Oxford University Press, Oxford.

Manacorda, M., A. Manning and J. Wadsworth (2006), "The Impact of Immigration on the Structure of Male Wages: Theory and Evidence from Britain", CEP Discussion Paper 754, London School of Economics.

Ottaviano, G. and G. Peri (2008), "Immigration and the National Wages: Clarifying the Theory and the Empirics", NBER Working Paper 14188.

Pischke, J. S. and J. Velling (1997), "Employment Effects of Immigration to Germany: An Analysis Based on Local Labor Markets", Review of Economics and Statistics, 79, pp. 594-604. 
Scheldon, G. (2003), „Die Auswirkung der Ausländerbeschäftigung auf die Löhne und das Wirtschaftswachstum in der Schweiz", in: H. R. Wicker, R. Fibbi, W. Haug (eds), Migration und die Schweiz, Seismo Verlag Zurich. pp. 335-367.

Stalder, P. (1991a), Regime Transitions, Spillovers and Buffer Stocks - Analysing the Swiss Economy by Means of a Disequilibrium Model, Lecture Notes in Economics and Mathematical Systems, Springer, Berlin.

Stalder, P. (1991b), "A Macro Disequilibrium Model for Switzerland", Recherches Economiques de Louvain, 2, pp. 125-158.

Stalder, P. (1994), "Excess Demand, Capacity Adjustment and Price Setting An Econometric Model for Swiss Manufacturing Based on Survey Data", KOF-Arbeitspapier 46, Konjunkturforschungsstelle der ETH, Zürich.

STAlder, P. (2001), „Ein ökonometrisches Makromodell für die Schweiz“, Quartalsheft 2/2001, Schweizerische Nationalbank, pp. 62-89.

Stalder, P. (2002), "The Changing Role of Foreign Labor and Female Participation: Impacts on Wage-Price Dynamics and Equilibrium Unemployment in Switzerland", paper presented at the Central Bank Workshop on Macroeconomic Modeling, Federal Reserve Board, Washington DC.

STAlder, P. (2008), „Personenfreizügigkeit: Auswirkungen auf den Arbeitsmarkt und das Wirtschaftswachstum", Die Volkswirtschaft, 11/2008, pp. 28-32.

Winter-Ebmer, R. and J. Zweimüller (1999), "Do Immigrants Displace Young Native Workers: The Austrian Experience", Journal of Population Economics, 12, pp. 327-340.

\section{SUMMARY}

The agreement with the European Union on liberalized migration had sizable effects on the Swiss economy. Simulations with a macroeconometric model show that the agreement mitigated the incidence of labor shortages and stimulated business investment, giving rise to an increased growth potential. The inflow of new immigrants also affected the demand-side of the economy by boosting consumption and housing investment. As the supply-side effects prevailed, inflation was dampened. Monetary policy reacted by pursuing a more expansionary course. Annual GDP growth was raised by half a percentage point in the upswing 2004-2008. However, as the employment effect was of similar size, the widely expected productivity gains did not materialize. Moreover, the unemployment rate was lifted by 0.5 to 0.7 percentage points and household suffered from lower real wage growth. 
The consequences of the migration agreement over a full economic cycle are more difficult to assess. If the increased flexibility of labor supply observed in the recent upturn carries symmetrically over to recessions, the migration agreement reinforces the swings in GDP and employment growth but dampens the swings in unemployment and inflation. In contrast, if the reaction of migration flows to rising and falling labor demand is asymmetric, unemployment might increase over the cycle because recovering labor demand attracts additional foreigners while the formerly dismissed workers remain in the unemployment pool. These different possibilities are illustrated in the paper by additional model simulations. 